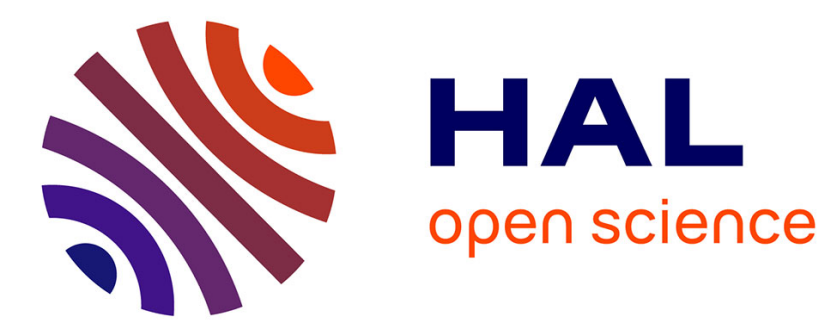

\title{
Reducing emissions from deforestation and degradation: What contribution from carbon markets?
}

\author{
Valentin Bellassen, R. Crassous, L. Dietzsch, S. Schwartzman
}

\section{To cite this version:}

Valentin Bellassen, R. Crassous, L. Dietzsch, S. Schwartzman. Reducing emissions from deforestation and degradation: What contribution from carbon markets?. [Research Report] 14, auto-saisine. 2008, 44 p. hal-01190162

\author{
HAL Id: hal-01190162 \\ https://hal.science/hal-01190162
}

Submitted on 1 Sep 2015

HAL is a multi-disciplinary open access archive for the deposit and dissemination of scientific research documents, whether they are published or not. The documents may come from teaching and research institutions in France or abroad, or from public or private research centers.
L'archive ouverte pluridisciplinaire HAL, est destinée au dépôt et à la diffusion de documents scientifiques de niveau recherche, publiés ou non, émanant des établissements d'enseignement et de recherche français ou étrangers, des laboratoires publics ou privés. 


\title{
REDUCING EMISSIONS FROM DEFORESTATION AND DEgRAdATION: WHAT CONTRIBUtION FROM CARBON MARKETS?
}

\author{
Valentin Bellassen ${ }^{*}$, Renaud Crassous ${ }^{\dagger}$, Laura Dietzsch $^{\ddagger}$ and Stephan Schwartzman ${ }^{\S}$
}

Tropical deforestation is responsible for $15-20 \%$ of total man-made emissions of greenhouse gases. In December 2007, at the international conference of Bali, the United Nations acknowledged that a viable solution to climate change must include a mechanism to limit deforestation and forest degradation. Today, the most widely used economic tool to reduce emissions is carbon markets: caps on emitters, and trade allowed between emitters and reducers, drive a price signal on carbon and provide incentives to control emissions. This report examines the different possibilities to broaden the range of this tool so that it helps reduce emissions from deforestation. The three main possibilities presented are a tax-based fund, the use of auctions revenues, and the issuance of tradable credits. The report does not discuss other instruments unrelated to carbon-related payments.

We first summarize existing information on the causes of deforestation, and the impact forest loss has on the global climate. To the contrary of a commonly held view, we find that farmers, more than loggers, are driving deforestation. Some, mostly in Africa, cut the forest to grow staple crops, while others, especially in South America, do so in response to the increasing demand for commercial crops and cattle.

Building on this analysis, we describe the different possibilities to link carbon markets to the fight against deforestation. In the latter case of the issuance of tradable credits, we find that while carbon markets could substantially increase the amount of funding available to develop projects and programs that reduce deforestation, demand for carbon credits must keep up with this potential new source of supply, probably around one billion ton of $\mathrm{CO}_{2}$ per year. As an analysis conducted by EDF shows, the emission caps currently advocated by the European Commission for Europe and by the Lieberman-Warner bill for the US would create enough demand to generate a price signal around $20 € / \mathrm{tCO}_{2}$. Other solutions such as reserve prices in auctions or credits banking have been put forward to mitigate the risk of too many deforestation credits flooding carbon markets.

In any case, reducing deforestation and maintaining a high price signal on carbon markets are like conjoined twins in the fight against climate change. Their link can be both a source of strength and vulnerability, but they eventually are both essential to achieve the ultimate goal of stabilizing the climate.

\footnotetext{
* Valentin Bellassen is a researcher at Mission Climat of Caisse des Dépôts and is concurrently undertaking his PhD at Laboratory of Climate and Environmental Sciences (LSCE) on forest management. His research areas include the voluntary market and forestry projects. Contact: valentin.bellassen@caissedesdepots.fr - + 33158501975

${ }^{\dagger}$ Renaud Crassous is a researcher at the International Research Center on Environment and Development (CIRED). His research areas include modelling energy and carbon markets. Contact: crassous@centre-cired.fr - + 33143947320

${ }^{\ddagger}$ Laura Dietzsch is a researcher at the Amazon Institute for the Environmental Research (IPAM). As a Brazilian environmentalist, her research areas include the causes and remedies to deforestation in Brazil. Contact: lauradi10@gmail.com

$\S$ Stephan Schwartzman is the co-director of the international program of the Environmental Defense Fund (EDF). He has worked in Brazil for many years and is one of the leading world experts on deforestation.

Contact: sschwartzman@environmentaldefense.org - +1 (202) 5723337
} 


\section{ACKNOWLEDGEMENTS}

The authors first wish to thank the Environmental Defense Fund, Amazon Institute for Environmental Research and Federal University of Minas Gerais for their useful contributions to this report.

The authors also wish to thank everyone they encountered in the course of preparing this report, especially Sandra Brown (Winrock International), Yves-Marie Gardette (ONF), David Kaimowitz (CIFOR), Ruben Lubowski (EDF), and Romain Pirard (IDDRI) for their careful reading and constructive criticism.

Note: All figures of this report are given in euros and tons of $\mathrm{CO}_{2} \mathrm{e}$. The conversion rates used are 0.65 euro/dollar and $3.66 \mathrm{tCO}_{2} \mathrm{e} / \mathrm{tC}$. 
INTRODUCTION

I. Deforestation AND GREENHOUSE GAS EMISSIONS, WHAT IS AT STAKE? $\mathbf{5}$

A. Deforestation globally: $15-20 \%$ of greenhouse gas emissions $\quad 5$

B. Deforestation at the regional level: a tale of three continents 9

C. Deforestation nationally: Brazil and Indonesia in the limelight $\quad 10$

$\begin{array}{ll}\text { D. Why do people cut the forest? } & 12\end{array}$

II. Forests in the Existing Tools to Fight Climate Change 17

$\begin{array}{ll}\text { A. History of the issue at the UN } & 17\end{array}$

B. The close link between EU ETS and the price of forestry credits 18

$\begin{array}{ll}\text { C. Deforestation remains restricted to funds and the voluntary carbon market } & 18\end{array}$

\section{Measurement and Monitoring Stakes for Carbon Related Payments 20}
A. Remote sensing techniques are operational to map land-use changes
B. Mapping carbon stocks remains a challenging exercise 21
C. Upcoming technological improvements 22
D. Non-permanence $\quad 22$
E. Leakage

IV. Brazilian Lessons: Money, Good Governance and Monitoring TeCHnology Can Reduce Deforestation

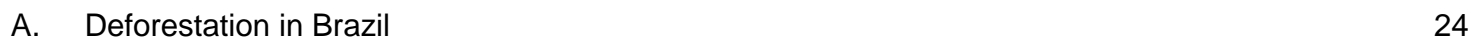

B. Amazon Region Protected Areas $\quad 25$

C. Other Brazilian Initiatives: National Plan to Combat and Prevent Deforestation, Satellite-based environmental licensing, and the Zero Deforestation Pact $\quad 27$

\section{How Could Carbon Markets Be Used? 28}

A. The theoretical carbon value needed to avoid deforestation 28

B. From theoretical opportunity costs to effective implementation: the low-hanging fruits of a tall tree 30

C. An effective price signal: how can REDD be linked to carbon markets? 32

D. The hurdles from the supply side: a matter of baselines 34

E. The hurdles from the demand side: how much can be bought? 35

F. The medium-term issue: full incorporation of forests in the international carbon market $\quad 37$

Annex 1. Published Figures of Emissions from Deforestation 39

ANNEX 2. THE COST OF AVOIDING DEFORESTATION - ESTIMATES FROM BOTTOM-UP APPROACHES $\quad 40$

$\begin{array}{ll}\text { REFERENCES } & 41\end{array}$

Research Publications of the Mission Climat 44 
Each year, mature and growing forests store a quarter of total anthropogenic emissions into their wood and soils. This useful service to moderate climate change is put to use by the Kyoto Protocol: it is already possible to earn carbon credits by planting forests. However, the Protocol says nothing about deforestation, in particular in tropical areas, which is responsible for about a fifth of global man-made emissions. It does not say more about forest degradation, that is the diminution of the carbon stock of land that nevertheless remains a forest, which generally happens when old forests are selectively logged for high value timber. This equation drove the United Nations to endorse Reducing Emissions from Deforestation and Degradation (REDD) as a means to mitigate climate change during its last international conference in Bali, December 2007. The endorsement spurred a new wave of research and negotiations, with the explicit aim of agreeing on a detailed mechanism by the end of 2009.

The first thing to agree upon is the definition of a forest. As the FAO has it, a forest is a patch of land, bigger than half a hectare, with at least $10 \%$ of its area under tree cover. Trees are understood as woody vegetation that reaches more than 5 meters in height at maturity. In the climate arena, the Kyoto Protocol leaves more room for manoeuvre. Countries may chose a minimal size ranging $0.05-1$ hectare, a minimal canopy cover ranging $10-30 \%$ and a minimal height ranging 2-5 meters. Such details matter: the size of the area defined as forest varies considerably depending on the definition (Figure 1). In terms of landscapes, lower thresholds will include land use mosaics where forests and fields are closely intertwined whereas higher thresholds will only capture remote mature forests.

Figure 1 - Area covered by forests depending on forest definition

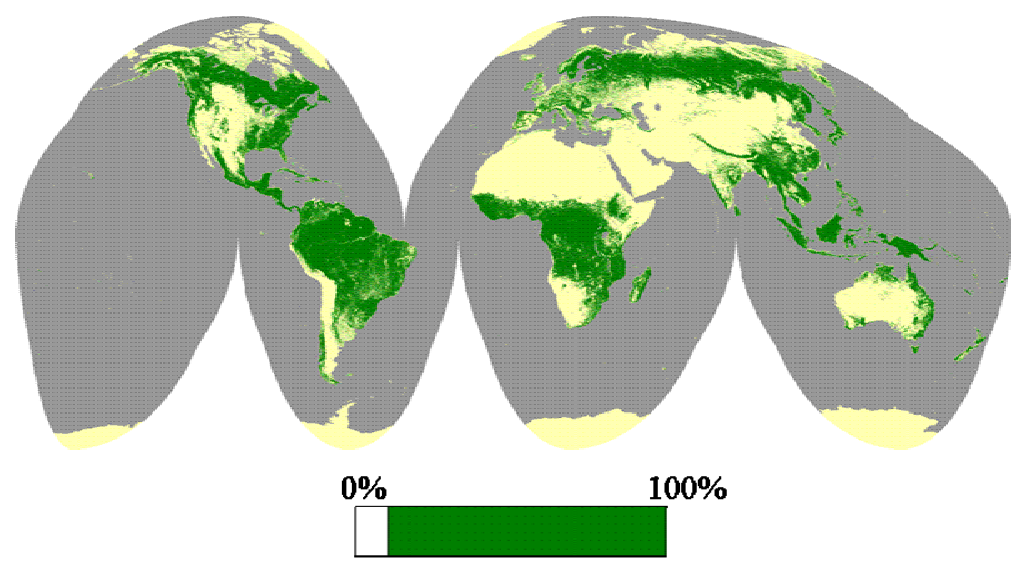

Applied tree cover threshold

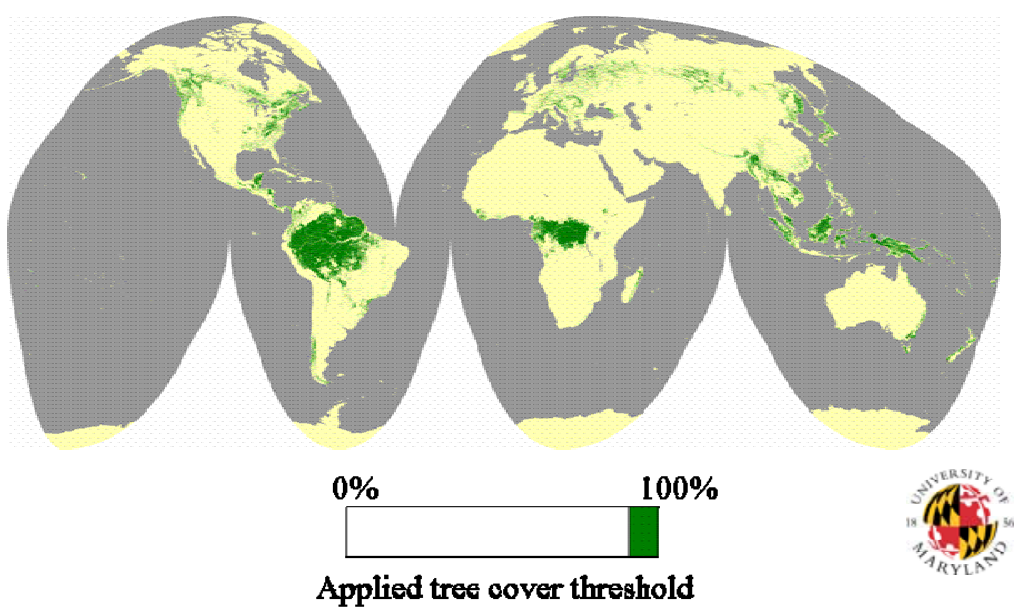

These maps are obtained from satellite images (MODIS) that allow the detection of tree cover at a $1 \mathrm{~km}$ resolution. Areas with at least 10\% tree cover (left) are much larger than areas with at least $90 \%$ tree cover (right). 
Depending on the cover density and where the forest is located, cutting it leads to various degrees of warming. The level of threat also depends on case-specific human pressure: in China, a logging ban is strongly enforced and forests are recovering (although Chinese timber imports drive large-scale deforestation in Indonesia and other countries) whereas in Brazil, demand for meat and soybeans drives the deforestation front further and further into the Amazon.

Without losing sight of such complexity, this report tries to summarize existing knowledge on deforestation. Building on the understanding of the causes of deforestation and their impact on climate then allows a better grasp on current proposals to link deforestation to carbon markets.

\section{DEFORESTATION AND GREENHOUSE GAS EMISSIONS, WHAT IS AT STAKE?}

\section{A. Deforestation globally: 15-20\% of greenhouse gas emissions}

\section{Emissions from deforestation: less than from energy, more than from transportation}

The IPCC best guess for emissions from deforestation puts them at $8.7 \mathrm{GtCO}_{2} \mathrm{e} / \mathrm{year}$ in 2004 . This figure is split between $5.8 \mathrm{GtCO}_{2} \mathrm{e} / \mathrm{yr}$ from deforestation stricto sensu and $1.9 \mathrm{GtCO}_{2} \mathrm{e} / y e a r$ from drained wetlands (be they peat forests or other kinds of swamps). These gross emissions from the forestry sector represent $17 \%$ of global greenhouse gas emissions in 2004, making forestry the third highest emitting sector after energy supply and industry. Another widely cited figure from IPCC is the part of deforestation stricto sensu in global $\mathrm{CO}_{2}$ emissions which ranges 5-25\%. Half of the uncertainty comes from the data used to compute deforestation rates. Relying on satellite data rather than country statistics puts the best guess towards the lower end of the range, at $3.6 \mathrm{GtCO}_{2} \mathrm{e} /$ year for deforestation stricto sensu. The other half comes from the uncertainty in forest carbon data. A recent study by Gibbs has analyzed eight major forest biomass carbon databases to create the first complete set of national forest carbon stock estimates. The study concludes that a range of options exists to address the technical challenges of measuring forest carbon, and that these will continue to improve in response to policy signals. Readers interested in a detailed analysis of global deforestation figures shall refer to Annex 1.

Figure 2 - Global greenhouse gas emissions per sector in 2004 (total: $50 \mathrm{GtCO}_{2} \mathrm{e}$ )

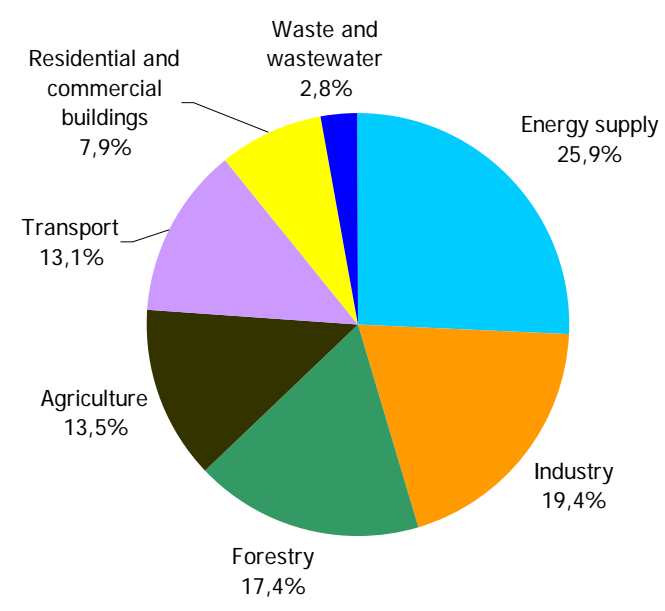

With $17 \%$ of global greenhouse gas emissions in 2004, forestry (gross emissions from deforestation stricto sensu and drained wetlands) amounted to $8.7 \mathrm{GtCO}_{2} \mathrm{e}$.

Source: IPCC 2007.

These figures do not take into account carbon emissions due to forest degradation. Over the Brazilian Amazon, these amount to $25 \%$ of emissions from deforestation sensu stricto. This ratio could be higher in Africa and Southeast Asia where selective logging and fuelwood collection are reputedly a more important phenomenon. 


\section{The timescale of trees: why the atmosphere cares more about deforestation than reforestation}

Deforestation emits greenhouse gases for two main reasons: burning and decaying. Farmers use fire to get rid of non-valuable woody parts such as stumps and tree crowns, or even stems when their needs for wood are already fulfilled. In the short-term, the resulting ashes also act as a fertilizer for the deforested plot. Greenhouse gas emissions from biomass burning mainly consist of $\mathrm{CO}_{2}$, but some methane $\left(\mathrm{CH}_{4}\right)$ and nitrous oxide $\left(\mathrm{N}_{2} \mathrm{O}\right)$ is also emitted (see Figure 3). What resists burning is left to decay, which usually occurs within 10 years. In the long term, decaying is also the fate of the wood extracted before burning though the time-scale varies widely depending on what it is used for.

Figure 3 - Types of greenhouse gases emitted through deforestation

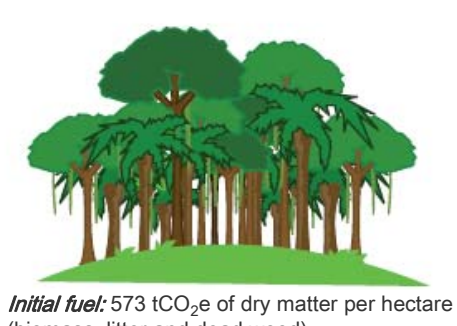

(biomass, litter and dead wood)
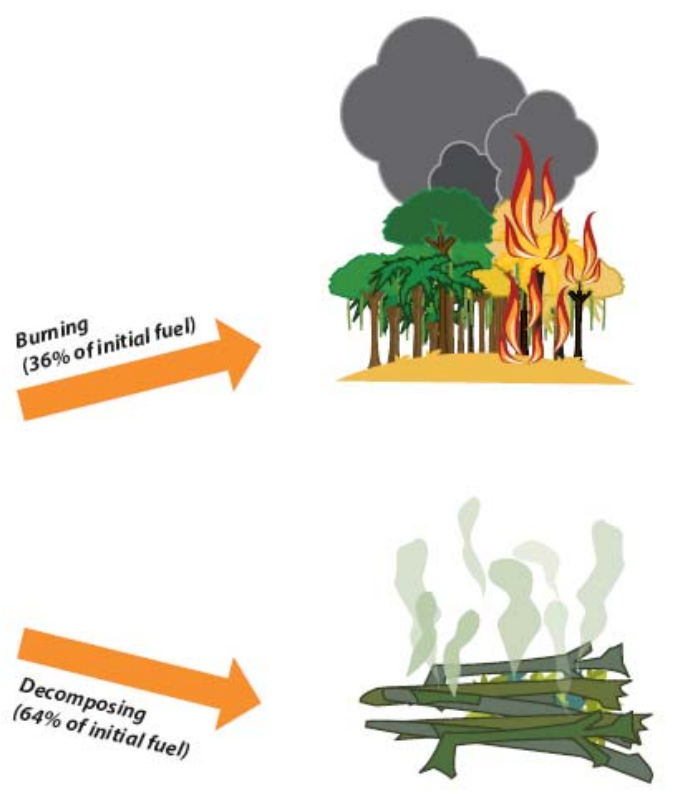

Resulting emissions for one hectare of tropical forest (tCO2e/ha)

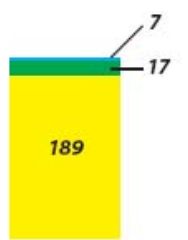

$\mathrm{N}_{2} \mathrm{O}$ emissions (tCO2e/ha) $\mathrm{CH}_{4}$ emissions (tCO2e/ha) $\mathrm{CO}_{2}$ emissions (tCO2e/ha)

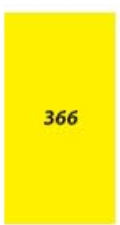

Greenhouse gas emissions from deforestation are due to two processes: burning and decomposing. Emissions consist mainly of $\mathrm{CO}_{2}$ but some methane $\left(\mathrm{CH}_{4}\right)$ and nitrous oxide $\left(\mathrm{N}_{2} \mathrm{O}\right)$ is emitted when biomass is burnt. This general pattern does not apply to decaying in swamps, but deforested lands are unlikely to be kept under water.

Source: Mission Climat from IPCC 2006 data.

The soil can also be a source of emissions. But contrary to icebergs, this hidden part of forest carbon is much less affected by clearings. When it is tilled for agriculture and deprived of carbon inputs from dead grass, leaves or wood, the soil releases on average $8 \%$ of its carbon content. But when forest is converted to pasture, the amount of soil carbon varies less and can even increase. In any case, this variation is seldom worth the price of measuring it: projects that plant trees for carbon credits are satisfied with proving that soil carbon increases but they do not claim carbon credits for it.

In this process, the timescale is paramount: when a forest is cleared, its carbon stock enters the atmosphere entirely within ten years. When a forest is planted, its carbon stock will need more than a hundred years to get close to the levels of primary rainforests. In the short term, it thus takes the planting of ten hectares of new forests to make up for the loss of one hectare of old-growth forest.

\section{One hectare of forest, how much in carbon?}

Assigning an amount of carbon for each hectare of forest is a difficult task. The result depends on three parameters: the scope of carbon pools taken into account, the local conditions (soil, climate, species), and the management (e.g., primary forest, selective logging, short rotations). 
- $\quad$ The scope of carbon pools considered

As with greenhouse gas inventories for industrial firms, the carbon content of forests depend on the scope of the inventory. The IPCC considers it good practice for national inventories to provide an estimate for all five carbon pools: aboveground biomass, root biomass, litter, dead wood, and soil carbon (Figure 4). As mentioned however, carbon projects in the forest sector usually limit their claim to the aboveground biomass pool which is easiest to measure and the most affected by human practices.

\section{Figure 4 - Carbon content of the different pools of a primary rainforest}

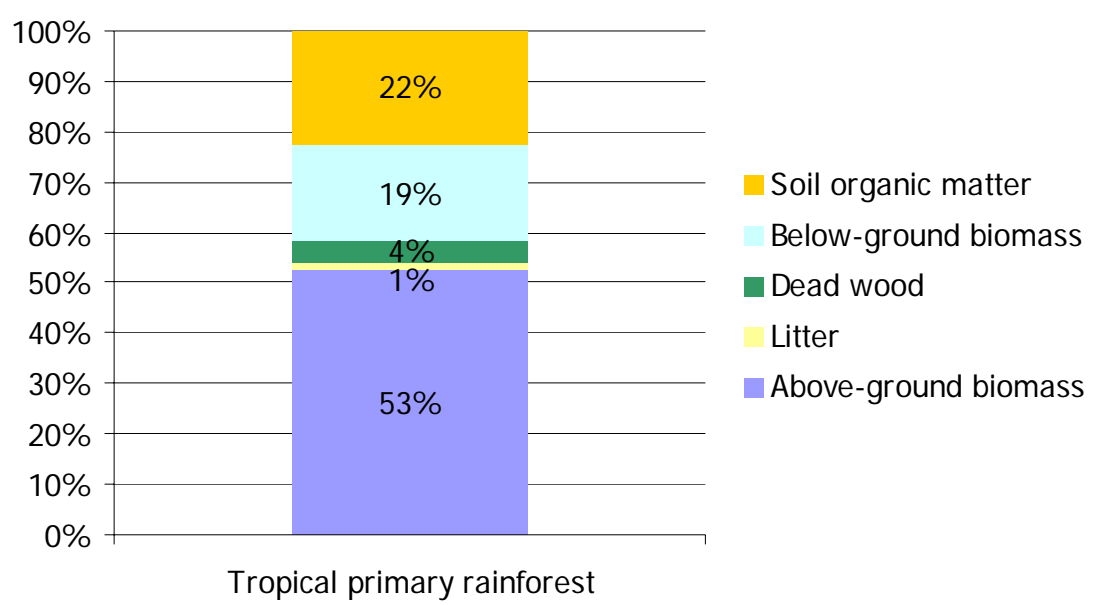

Source: IPCC 2006

- $\quad$ Local conditions

As a general rule of thumb, the more moisture, heat and nutrients they have, the more carbon forests store in their wood. The first two factors explain why tropical rainforests have on average a larger stock of aboveground biomass (Figure 5).

Figure 5 - Carbon content of forests

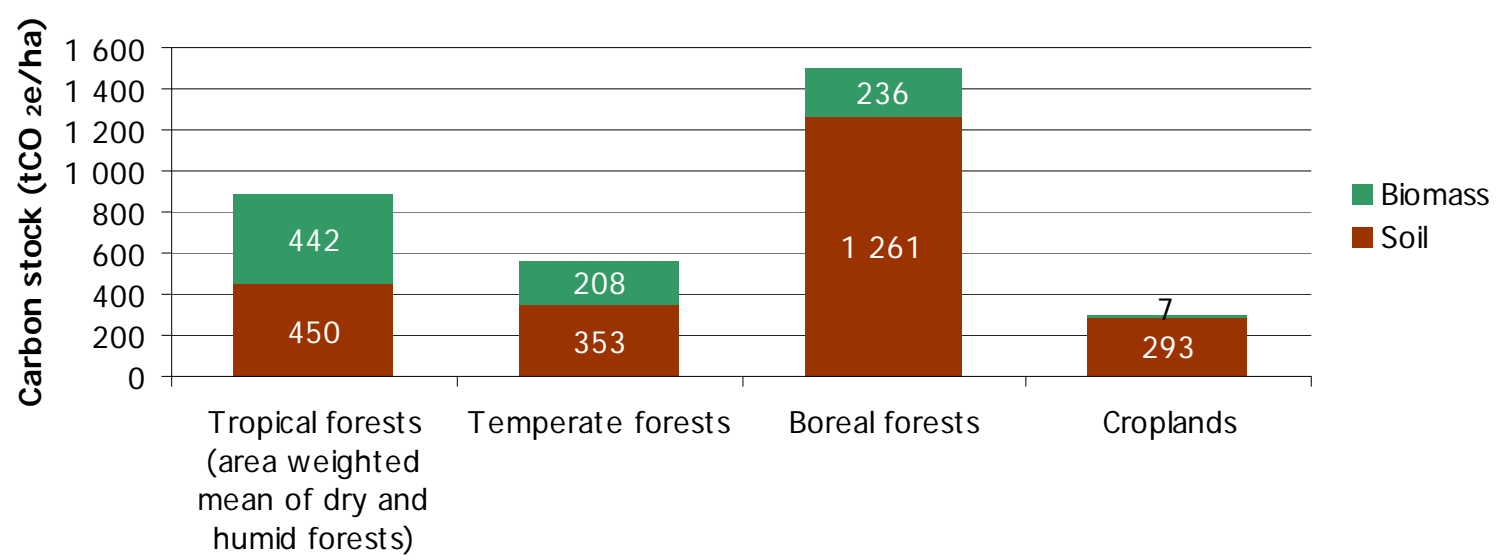

These global averages for different ecosystems illustrate the influence of scope, climate and management on the carbon content of forests. Due to their warm and moist climate, tropical forests store more carbon in biomass than their temperate and boreal counterparts. This effect is probably amplified by management practices: while most temperate forests have long been under management, many tropical forests are still unexploited. Finally, when the scope of carbon pools is expanded to include soils, boreal forests more than make up for their lower biomass stock.

Source: Mission Climat from IPCC 2000 data. 


\section{- Management practices}

Forest management practices have a strong influence on carbon stocks: the average age of managed European forests is kept low by long-term management. This maintains their carbon stock lower than its equilibrium value, but also makes them "sinks" as they use atmospheric $\mathrm{CO}_{2}$ to fuel their growth. On the other hand, tropical primary forests have larger stocks but these have reached equilibrium. In theory, they emit as much carbon through respiration and decay as they absorb, and do not influence the carbon content of the atmosphere. In practice however, their carbon stock is estimated to be slightly increasing due to anthropogenic effects such a nitrogen deposition and $\mathrm{CO}_{2}$ fertilization.

Accordingly, a difference in management practices may have an impact on carbon stocks (see Box 1). Reduced-Impact Logging for example, a technique that reduces "collateral damage" on neighbouring trees when selected trees are logged, can decrease $\mathrm{CO}_{2}$ emissions associated with forestry operations by $15-20 \%$ compared to more conventional management practices.

\section{Box 1. How much carbon is emitted from forest degradation?}

In the case of deforestation, the pattern is simple: emissions correspond more or less to the total amount of aboveground carbon. Emissions from forest degradation follow a more complicated pattern: when a forest is selectively logged, $10-30 \%$ of its total aboveground carbon pool is cut. Of this, only about $10 \%$ will end up as a wood product. The other $90 \%$ quickly oxidize and are thus entirely converted into $\mathrm{CO}_{2}$ within 10-20 years. Based on measurements in Brazilian logging concessions, Pearson estimates that a conventional logging event there releases about 60 $\mathrm{tCO}_{2} \mathrm{e} / \mathrm{ha}$. These emissions can be reduced to $50 \mathrm{tCO}_{2} \mathrm{e} / \mathrm{ha}$ for reduced-impact logging.

But as for the managed European forests, regrowth will soak up carbon and thus make up for part of these emissions. In terms of carbon accounting, current methodologies are therefore focused on the long term difference between primary, sustainably managed, and degraded forests. At this time-scale, forests with sustainable management plans tend to retain most of their carbon stock while those illegally or anarchically exploited can be slowly deforested.

If one was to nail down the carbon value of one hectare of forest, restricted to the above-ground biomass, the order of magnitude would therefore be $300 \mathrm{tCO}_{2} \mathrm{e}$. For tropical rainforests, the IPCC figures are around $600 \mathrm{tCO}_{2} \mathrm{e}$. Moreover, forests offer many well-recognized benefits other than carbon storage such as local climate moisture, flood prevention, wildlife habitat, ... For example, Silva Dias estimated that the conservation of more than $70 \%$ of the Amazon forest may be necessary to maintain the forest-dependent rainfall regime of the region. Most often however, these other benefits have a lower marketing potential than carbon: even if tropical forests are more famous for their biodiversity than for their carbon stock, the existing mechanisms to protect biodiversity do not have the financial clout of carbon markets.

\section{One ton may hide another}

Ancillary benefits are not the only reason why there is more to forests than their mere carbon content. Even when one focuses on their impact on global warming, forests intervene in at least three different manners:

- $\quad$ Greenhouse gases: the most evident impact of cutting down trees is to release their carbon content into the atmosphere in the form of greenhouse gases. Keeping this carbon in the wood therefore reduces global warming.

- $\quad$ Albedo: forests tend to be darker than other types of lands. This is especially true in high latitudes where grasslands are entirely covered by snow in winter while forests exhibit darker spots. Therefore, they tend to retain more heat from sun beams and have a warming effect in terms of albedo. 
- Evapo-transpiration and other heat fluxes: forests tend to "sweat" more than other types of lands. This locally absorbs heat from the surface, but this heat is released elsewhere high up in the atmosphere when the water vapour condenses. Other heat fluxes such as local wind patterns are also affected by forests. Overall, this effect tends to decrease surface temperatures.

The greenhouse effect is independent on the place on Earth where greenhouse gases are emitted and its intensity can be quantified fairly precisely. The two other effects are more difficult to grasp. The only way to get an idea of these combined effects on climate is to analyze different deforestation scenarios with global climate models. This has been done by Claussen with a model that shows an overall warming effect of tropical deforestation, and an overall cooling effect of boreal deforestation.

Unfortunately, the uncertainty associated with these models is still too high to convert this knowledge into a "climate currency" comparable to the tonnage of $\mathrm{CO}_{2}$ equivalent which allows comparison of all greenhouse gases in terms of climate impact: other modelling studies such as that of Betts suggest that even deforestation in Scandinavia still has an overall warming effect. As the scientific knowledge on climate improves and models converge towards more precise estimates, it may become possible to determine a conversion table for forest carbon, depending where deforestation takes place. In the meantime, as for fossil fuel emissions ${ }^{5}$, carbon finance deals with the only "climate asset" of forests that is measurable: their carbon content.

\section{B. Deforestation at the regional level: a tale of three continents}

According to the measurements of deforestation by Achard, the clearing of rainforests is the source of most emissions from deforestation: while other, drier forests accounted for at least one third of yearly tropical deforestation in the 1990s, they made up only about $15 \%$ of emissions due to their lower carbon content. Even in Africa where drier forest accounted for two thirds of deforested areas, they only accounted for one third of total emissions from deforestation. For all that, the clearing of dry forests is not to be neglected, even though few studies have been considering this issue.

As show in Table 1, the most recent trends in tropical rainforests reveal deep regional differences:

- $\quad$ Tropical America: larger forests, more deforestation

Tropical America contains most of the rainforests with an estimated 669 million hectares. It is also loosing more forest than other regions: between 2000 and 2005, tropical America made up about 60\% of all gross rainforest losses in the world.

- $\quad$ Tropical Asia: a picture of contrasts

In tropical Asia, the picture is mixed: while the "island countries" such as Indonesia, Malaysia or Papua New Guinea are quickly losing their forests, the forest cover is increasing in India. Just north of the tropical realm, China is also actively pursuing reforestation policies.

- $\quad$ Africa's rainforests: still standing, but increasingly degraded

Because of the lack of reception stations for satellite images in the Congo Basin, figures for African rainforests in the 1990s have a larger uncertainty. New sampling schemes have improved them for the most recent periods. In any case, it is clear that rainforest clearing is less intense than elsewhere: between 2000 and 2005, only 5\% of global rainforest clearings occurred in tropical Africa. Forest degradation stemming from unsustainable logging practices, although difficult to quantify at the regional scale, is probably a bigger threat in the short term.

${ }^{5}$ The greenhouse effect is not the only impact of fossil fuel emissions on climate either. Coal burning for example emits aerosols as well as $\mathrm{CO}_{2}$. The warming effect of $\mathrm{CO}_{2}$ is estimated to be higher than the potentially cooling effect of aerosols. 
Table 1 - Gross deforestation and net deforestation as measured by satellites

\begin{tabular}{|c|c|c|c|c|c|c|}
\hline Region & Forest type & Gross defo & ation & Net defor & tion & Sources \\
\hline & & Mha/yr & $\% / y r^{*}$ & Mha/yr & $\% / y r^{*}$ & \\
\hline $1990-20$ & & & & & & \\
\hline Tropical & America & & & & & \\
\hline & All & $4-4,4$ & & 4,1 & & DeFries 2002, Achard 2004 \\
\hline & of which Brazil & 1,6 & $n / a$ & $\mathrm{n} / \mathrm{a}$ & $n / a$ & INPE \\
\hline & Rainforest & 2,5 & $0,38 \%$ & 2,2 & $0,33 \%$ & Achard 2004 \\
\hline & Other & 1,9 & $\mathrm{n} / \mathrm{a}$ & 1,9 & $\mathrm{n} / \mathrm{a}$ & Achard 2004 \\
\hline Tropical & Africa & & & & & \\
\hline & All & $1,3-2,3$ & & 2,1 & & DeFries 2002, Achard 2004 \\
\hline & Rainforest & 0,9 & $0,43 \%$ & 0,7 & $0,36 \%$ & Achard 2004 \\
\hline & of which Congo Basin & 0,4 & $0,21 \%$ & 0,3 & $0,16 \%$ & Duveiller 2008 \\
\hline & Other & 1,5 & $\mathrm{n} / \mathrm{a}$ & 1,43 & $\mathrm{n} / \mathrm{a}$ & Achard 2004 \\
\hline Tropical & Asia & & & & & \\
\hline & All & $2,7-2,8$ & $1,00 \%$ & 2,3 & $0,82 \%$ & DeFries 2002, Achard 2004 \\
\hline India (pa & tly included in Tropical $A$ & & & & & \\
\hline & All & $\mathrm{n} / \mathrm{a}$ & $\mathrm{n} / \mathrm{a}$ & $-0,4$ & $-5,66 \%$ & Forest Survey of India 2006 \\
\hline $2000-20$ & & & & & & \\
\hline Tropical & America & & & & & \\
\hline & Rainforest & 3,3 & $0,51 \%$ & $\mathrm{n} / \mathrm{a}$ & $\mathrm{n} / \mathrm{a}$ & Hansen 2008 \\
\hline & of which Brazil & $2,2-2,6$ & $\mathrm{n} / \mathrm{a}$ & $\mathrm{n} / \mathrm{a}$ & $\mathrm{n} / \mathrm{a}$ & INPE, Hansen 2008 \\
\hline Tropical & Africa & & & & & \\
\hline & Rainforest & 0,3 & $0,15 \%$ & $\mathrm{n} / \mathrm{a}$ & $n / a$ & Hansen 2008 \\
\hline Tropical & Asia & & & & & \\
\hline & Rainforest & 1,9 & $0,58 \%$ & $\mathrm{n} / \mathrm{a}$ & $\mathrm{n} / \mathrm{a}$ & Hansen 2008 \\
\hline & of which Indonesia & 0,7 & $n / a$ & $n / a$ & $n / a$ & Hansen 2008 \\
\hline
\end{tabular}

\section{Deforestation nationally: Brazil and Indonesia in the limelight}

According to the FAO dataset (see Annex 1 for details), Brazil and Indonesia are by far the two countries most affected by deforestation. This ranking was confirmed by Hansen's remote sensing study: together, Brazil and Indonesia account for $60 \%$ of global rainforest deforestation. Based on these figures and assuming that rainforest clearing emits a conservative average $600 \mathrm{tCO}_{2} \mathrm{e} / \mathrm{ha}$, one gets annual emissions of 1.5 billion tons of $\mathrm{CO}_{2} \mathrm{e}$ for Brazil and 0.4 billion tons of $\mathrm{CO}_{2} \mathrm{e}$ for Indonesia, that is respectively $62 \%$ and $46 \%$ of these countries total greenhouse gas emissions. The figure for Indonesia is very conservative as peat forests, often cleared for palm oil there, release more than twice as much $\mathrm{CO}_{2}$ as the average rainforest.

The Figure 6, based on FAO data, gives an idea of the differences in national forest trends. These national specificities have their importance when it comes to understanding the positions that countries defend at the UN negotiating table on the future link between REDD and carbon markets. As this report comes to each of the main negotiating issues, these national positions will be presented in specific "Negotiation Boxes". 
Figure 6 - Differing forests, differing concerns

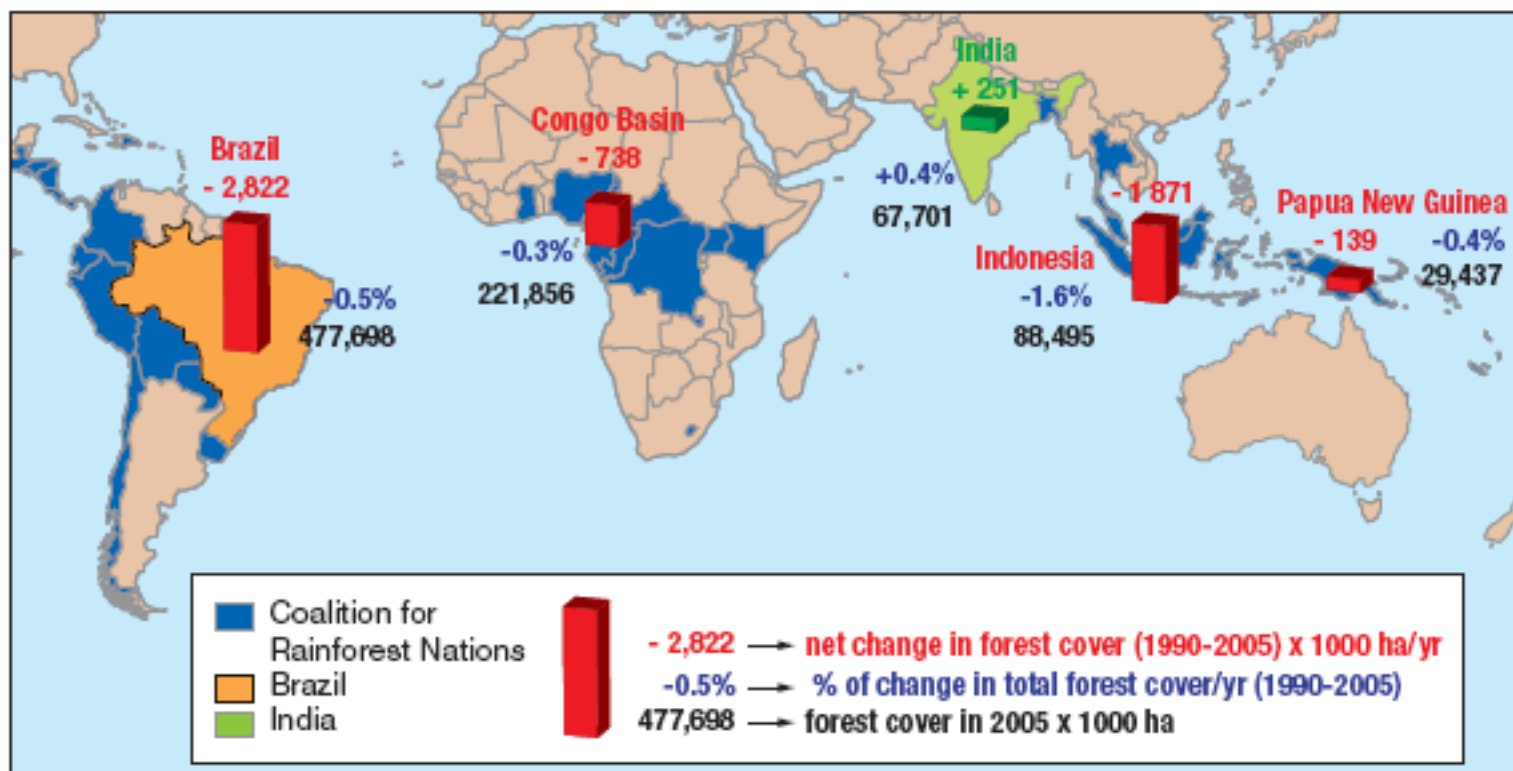

While Brazil and Indonesia are deforesting millions of hectares per year, India is reforesting. The situation is different in the Congo Basin, where forest degradation, rather than deforestation, is a more pressing issue.

Note: The Coalition for Rainforest Nations officially counts 15 countries. Through Its regular workshops, more than 30 countries (in blue on the map) try to harmonize their negotiating position on deforestation at the UN. The history of the Coalition is explained in part II.A. 


\section{Why do people cut the forest?}

Figure 7 - Map of the leading drivers of deforestation

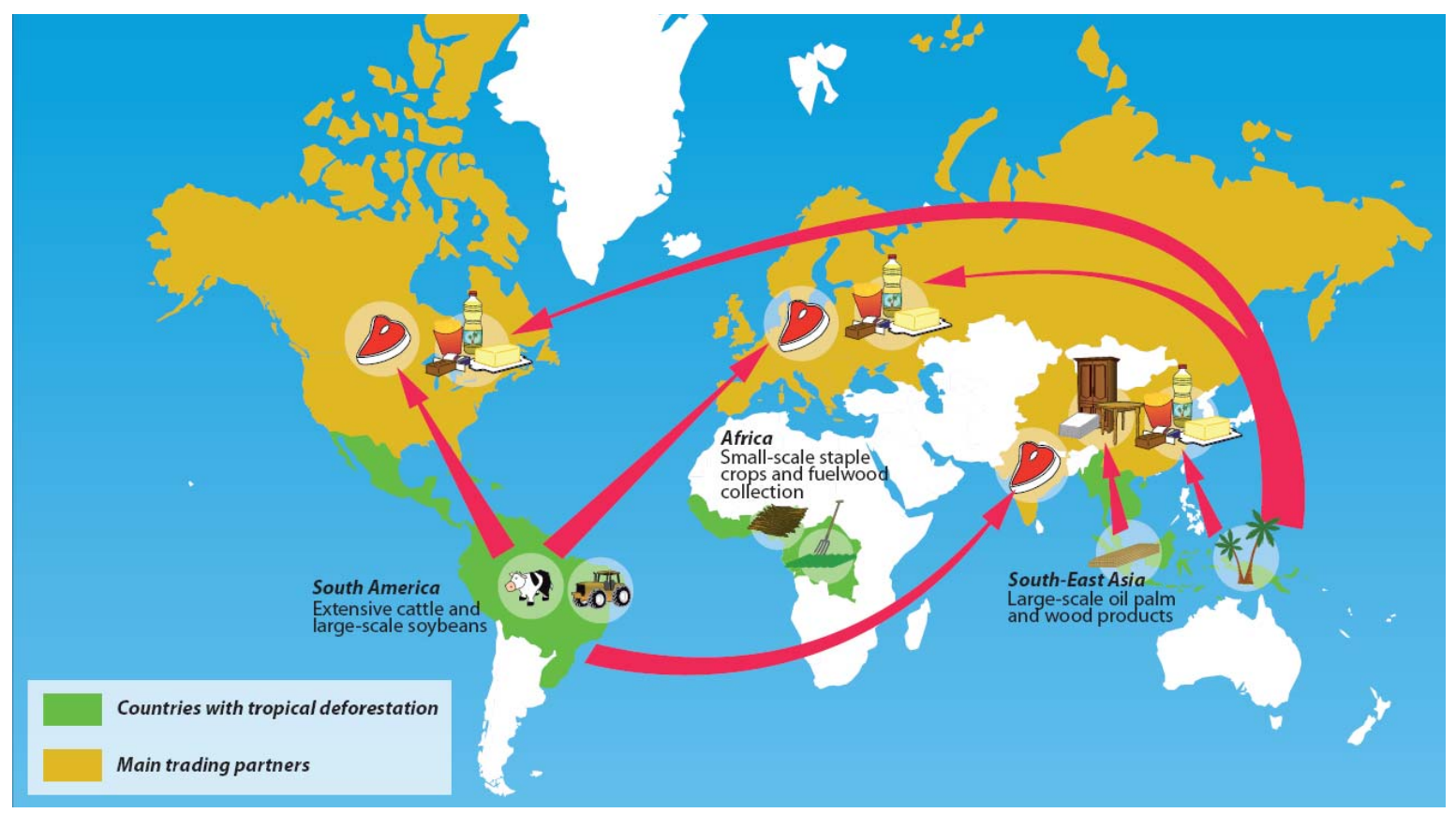

In South America, forests are most often cleared to grow cattle and soybeans while in South-East Asia, cultivation of oil palm and exploitation of wood products are the leading proximate causes of deforestation. In both cases, global demand for these commodities is the dominant underlying cause of deforestation. In Africa, deforestation tends to be driven by smallholders, through staple crops and fuelwood collection.

Source: Mission Climat of Caisse des Dépôts.

In order to effectively address deforestation anywhere, it is necessary to understand its specific local causes and dynamics. When small-scale farmers chop down a plot of forest in Africa, they may want to sell timber, to collect fuelwood, or to grow crops. Most often, they are actually interested in several of these outputs. Even when only considering the proximate causes - the output expected from deforesting - the reason to deforest is seldom unique. But to fully understand the process, one also has to assess the underlying drivers, that is the socio-economic context that drives people to seek such deforestation outputs.

\section{Agriculture is the most frequent proximate cause of deforestation}

Lands are not suitable for the same crops everywhere, and needs are not the same in every country. Agricultural and forestry policies also vary. This explains why land-use patterns following a deforestation event vary regionally: deforested land is mainly used for small-scale agriculture in Africa, while cattle ranching and large-scale soy cultivation predominate in the Amazon.

One has two ways to evaluate the regional importance of a proximate cause of deforestation. The first is to compile case studies. After reviewing 152 of these, Geist and Lambin found that agriculture (including animal pasture) is the most frequently cited proximate cause of deforestation. While this pattern is globally consistent, the type of agriculture, as well as the importance of others causes, varies around the world. As shown in Figure 8, cattle ranching is involved in more than $80 \%$ of deforestation cases in Latin America, but it plays a very small role in Asia and Africa where commercial timber and fuel wood collection are two important causes of deforestation. 
Figure 8 - Direct causes of deforestation vary around the globe

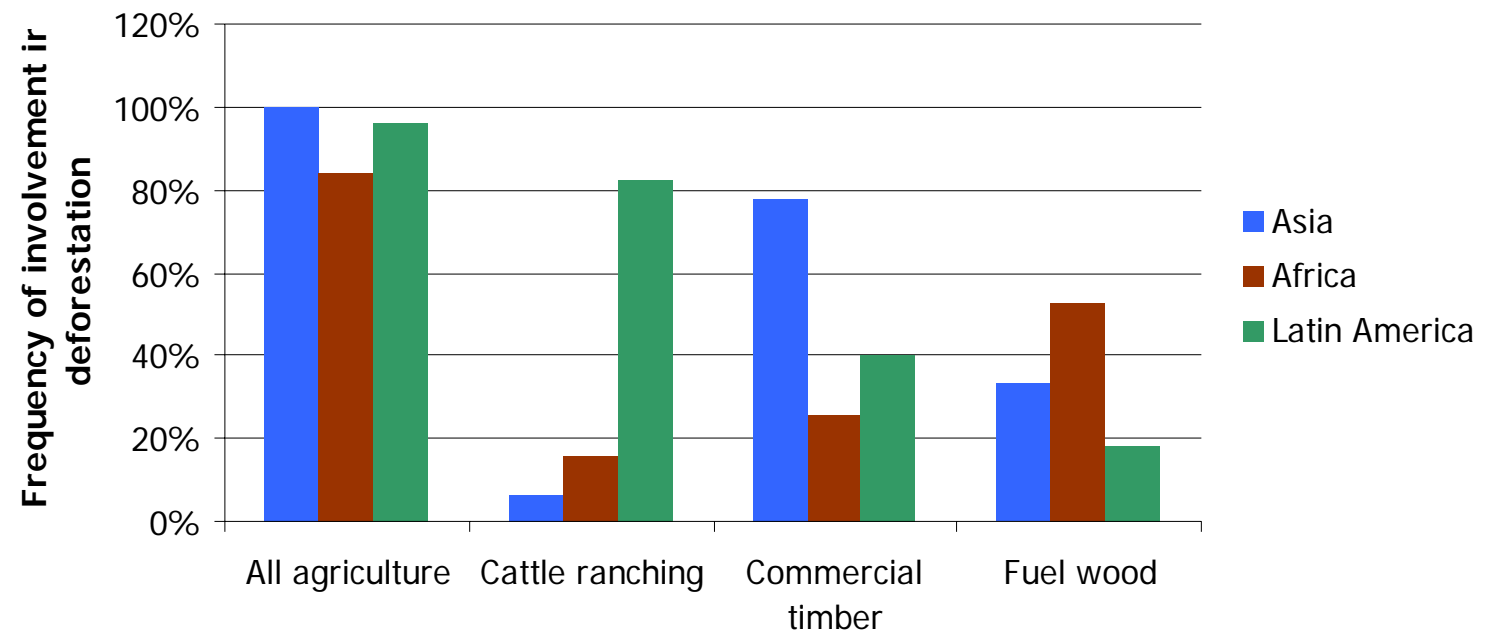

Agriculture is a leading motivation to deforest everywhere in the world. The type of agriculture however, as well as the importance of other proximate causes, are very specific to the region considered.

Source: Mission Climat of Caisse des Dépôts, adapted from Geist and Lambin 2002.

The second way consists in using satellite imagery and looking at what deforested lands turn into. Such analysis confirms the paramount role of cattle ranching in the Amazon, with about $70 \%$ of deforested land identified as cattle pasture in 2005 . The same technique also allowed the FAO to conclude that deforestation for large-scale ( $>25 \mathrm{ha}$ ) agriculture is the predominant pattern in Latin America and Asia, whereas in Africa forest conversion more often leads to small-scale agriculture.

Figure 9 - Types of agriculture practiced on deforested lands

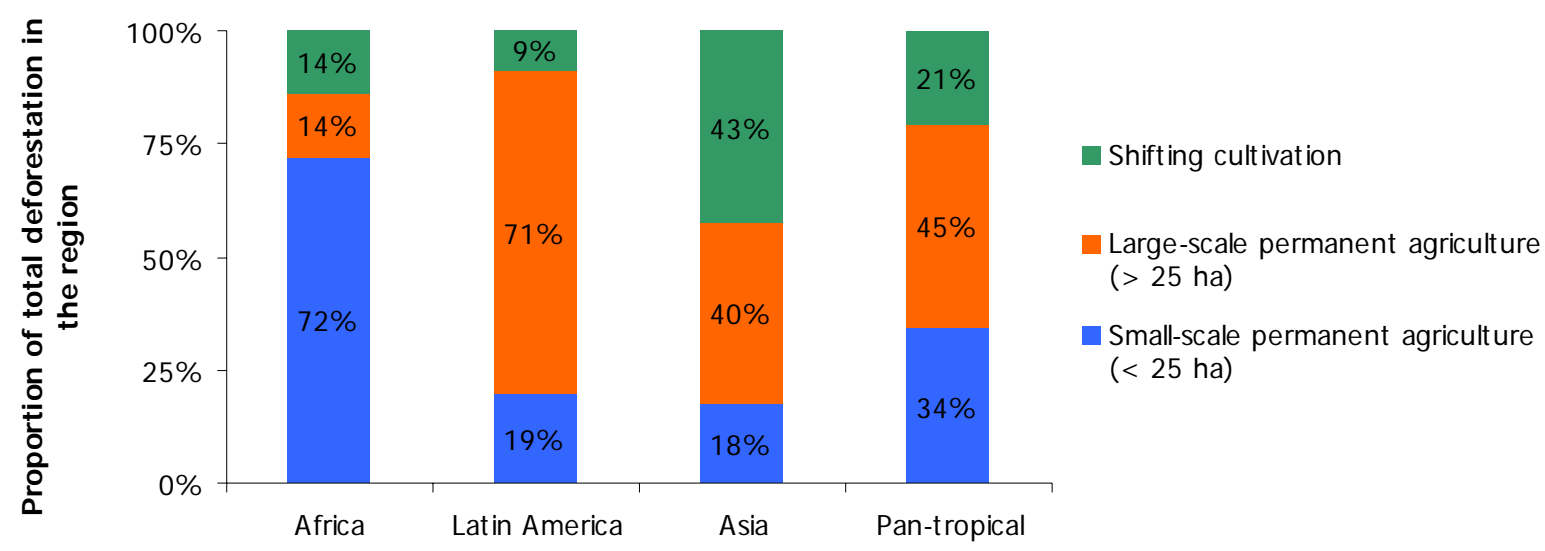

Large-scale agriculture is responsible for $71 \%$ of deforestation in Latin America, as opposed to Africa where deforestation is mostly driven by smallholders. In tropical Asia, shifting cultivation plays a large role and may be practiced at large scales. However, two recent studies by Curran and Griffiths in some parts of Indonesia give a higher weight to logging and largescale plantation establishment.

Source: Mission Climat of Caisse des Dépôts, adapted from FAO 2001.

While agriculture is clearly the first deforestation driver in the world, timber exploitation and fuel-wood collection are critically important for the less easily detectable process of forest degradation. Fuel-wood 
make up $8 \%$ of the global supply of primary energy and its production can lead to a long-term depletion of carbon stocks when forests are not managed properly. This pressure on forests is especially high in Africa where an estimated $90 \%$ of wood removals are used to meet energy needs. Unsustainable timber exploitation can also greatly deplete forests carbon stocks. Moreover, the tracks opened by logging companies to get into the forest often paves the way for farmers and cattle ranchers to settle in parts that would have otherwise been inaccessible.

\section{Underlying drivers: the central role of agricultural prices}

Underlying drivers of deforestation are more difficult to capture, but also more important to detect: as in medicine, it is more efficient to treat the cause of the illness rather than its symptoms. Wide-ranging studies point to economic drivers as the key to understand deforestation. In their comprehensive review, Geist and Lambin found that market conditions played a role in $81 \%$ of deforestation events. Moreover, the international prices of agricultural commodities have long been known to drive deforestation. In Cameroon, the deforestation rate between 1967 and 1997 was strongly correlated with macro-economic conditions, and in particular with the price of such cash crops as coffee or cacao. In Brazil, soy and cattle prices have be closely linked with the national deforestation rate since the year 2000. Kaimowitz and Angelsen put this in a nutshell after reviewing 150 economic models of tropical deforestation: higher agricultural prices stimulate more forest clearing.

Figure 10 - Link between deforestation and agricultural prices

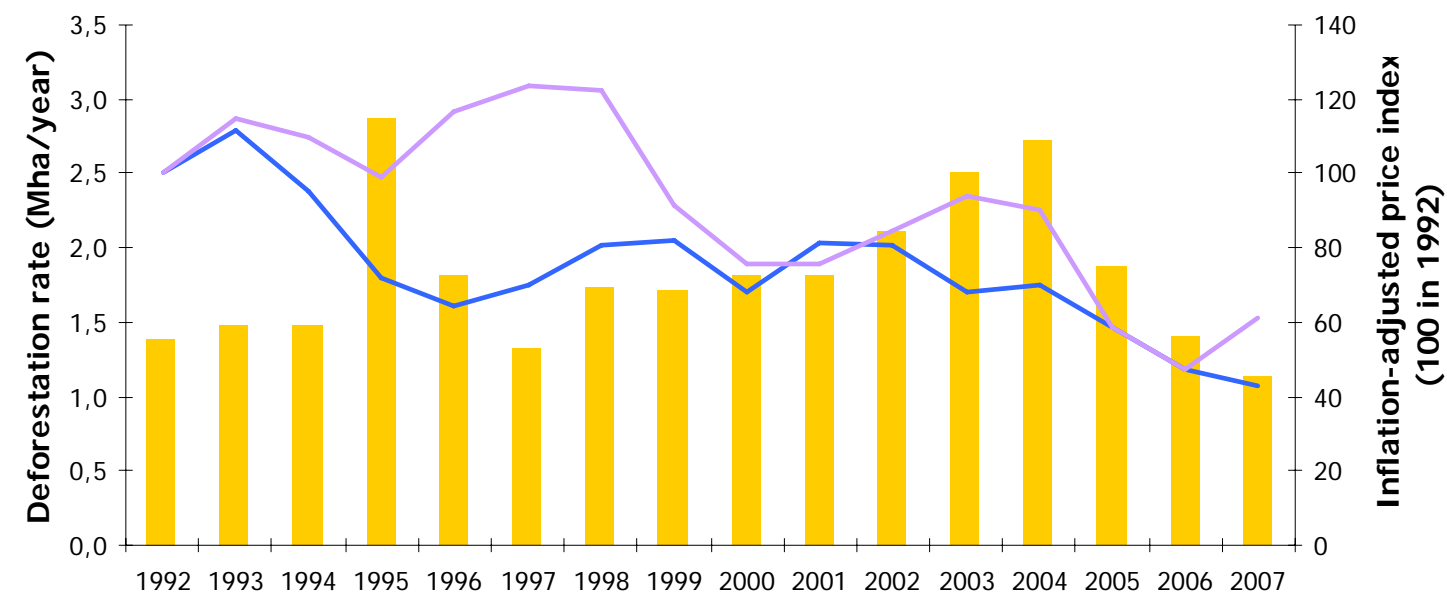

Deforestation in legal Amazonia (Mha/yr)

Cattle meat price index — Soybean price index

Since 2000 , soy prices, and to a lesser extent cattle prices, are strongly linked with deforestation. This keeps being verified as the recent increase in soy prices comes along a dramatic rise in deforestation in 2008. However, the high resolution measurements of deforestation for 2008, comparables to the temporal series presented on this figure, are not yet available. 
Increasingly, large-scale deforestation is driven by global demand for agricultural commodities. This trend can, in the absence of incentives to the contrary, be expected to continue, since agricultural land suitable for major agricultural commodities is largely in high-carbon, high-biodiversity forests inhabited by indigenous peoples (see Figure 11).

\section{Figure 11 - Untapped agricultural potential of forests}

Forest Area with High Potential for Soy, Palm Oil, or Sugar Cane

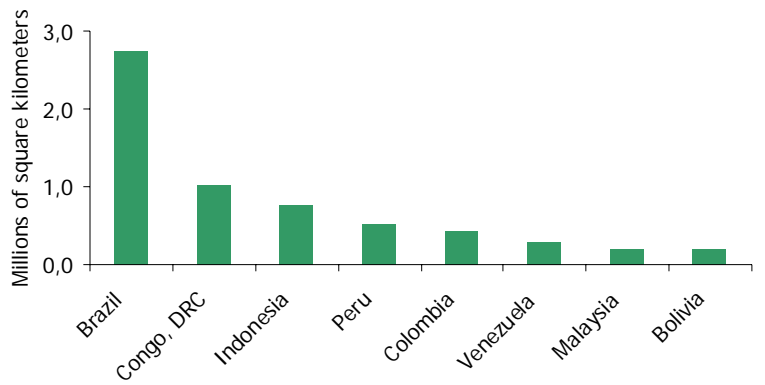

Forest Carbon on Lands with High Potential for Soy, Palm Oil, or Sugar Cane

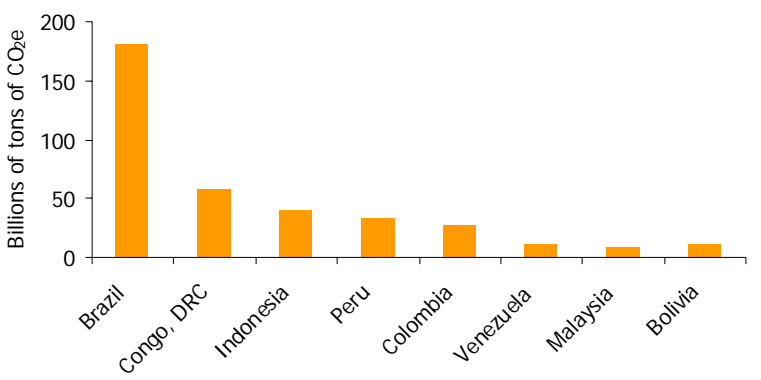

Large forest areas and forest carbon stocks on forested lands have suitable soil and climate for major drivers of tropical deforestation (soy, oil palm, sugar cane). Thirty-six per cent of the land suitable for any one of these crops is in Brazil.

Source: Stickler et al. 2007.

This central role of market conditions in driving deforestation leads to the general pattern of deforestation described by Hyde and Chomitz. Each major market (city) is surrounded by successive belts of activities: intensive agriculture, extensive agriculture, timber extraction, and primary forest. When the central market is too far, transportation costs for farm inputs and outputs make intensive agriculture less profitable than extensive agriculture. Then these costs reach a level at which agriculture is no longer profitable and is replaced by timber harvesting. As roads and new settlements decrease transportation costs, the width of each belt widens, cutting into primary forests (see Figure 12). This pattern is especially relevant in Brazil: as one draws closer to a city, farm gate price of beef rises and so does the deforestation rate. Based on this type of analysis, Arima found that a $10 \%$ increase in the urban price for beef would extend the "cattle ranching belt" by $260000 \mathrm{~km}^{2}$ into the forest. 
Figure 12 - The central role of markets in defining deforestation patterns

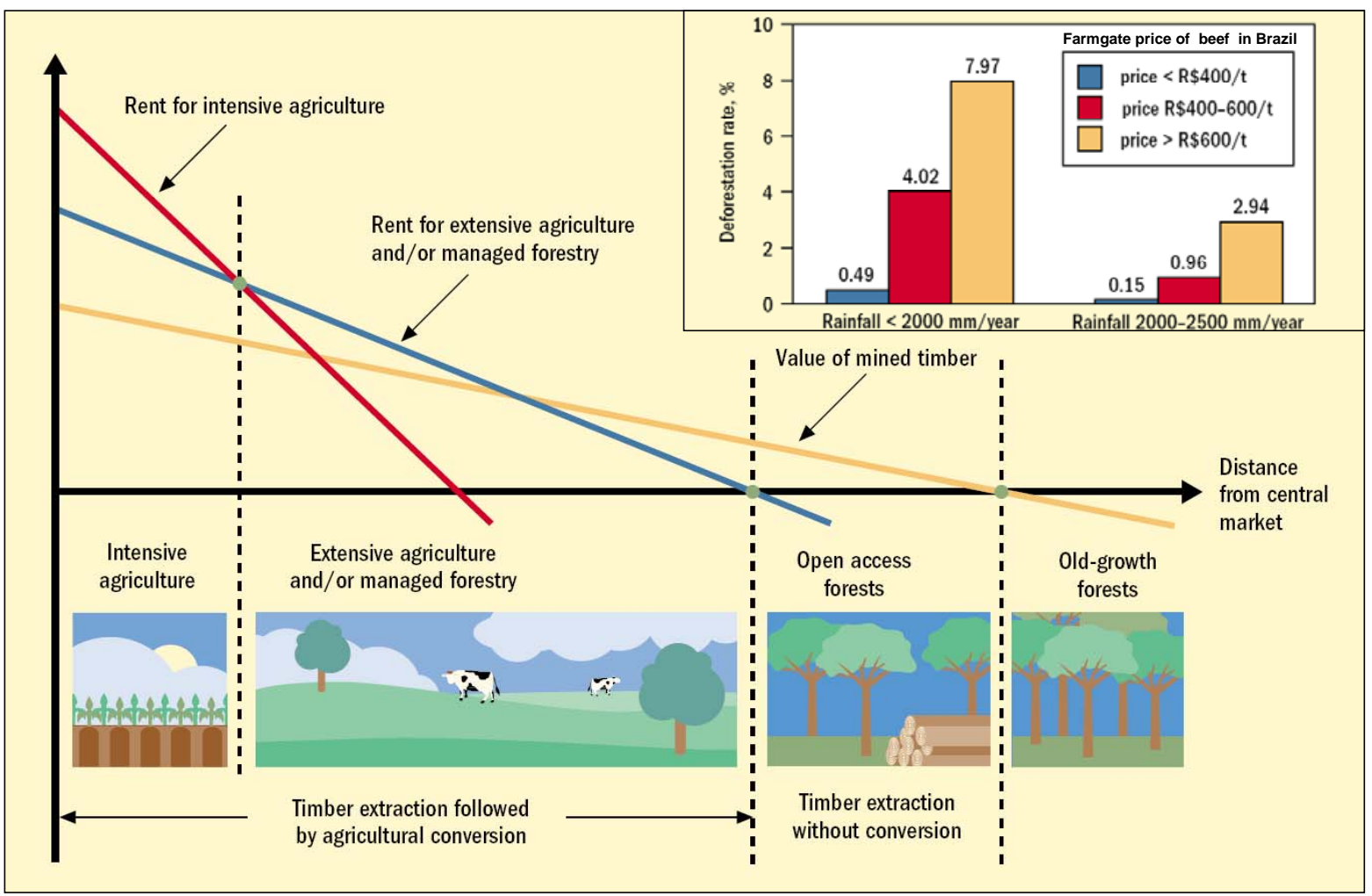

Deforestation patterns are driven by the distance from central markets: as transportation costs rise, deforestation slows, and the most profitable type of land use changes.

Source: Chomitz 2006.

By focusing on farmgate prices for agricultural commodities, we thus get a thorough understanding of underlying deforestation drivers: indeed, farmgate price are not only affected by international demand for agricultural commodities, but also local and national factors, such as exchange rates and land development policies, related to each country's macro-economic policies. Let us consider the example of eight specialised oil and mineral exporting countries studied by Wunder. An abundant inflow of foreign investment allows their governments to draw people to the cities by subsidising urban development. Moreover, their relatively high exchange rates diminish returns from agricultural and timber exports. As a result, their deforestation rates are lower than comparable non-exporting tropical countries. This pattern is not universal: in Indonesia for instance, oil exports are used to finance pulp mills which tend to increase deforestation rates. In any case, countries macro-economic policies can have an important impact on their rates of deforestation. Biofuel subsidies are another example recently studied of this potential impact. The findings of this study are summarized in Box 2.

Other underlying factors also can also explain the evolution of deforestation rates. This is particularly the case of institutional aspects such as land tenure. Securing land tenure through zoning has been shown to reduce deforestation. In China, a mix of logging bans, land-use planning decentralisation and subsidized forest plantation led the country on the road to net reforestation.

To the contrary, low enforcement of the legal framework or ill-designed planning policies may promote deforestation. In the Brazilian Amazon for example, about $40 \%$ of the land remains "terra devoluta", or "empty land", that is, state or federal public land not assigned to any particular use or category, or in conflict (with more than one claimant). While there are in theory legal means for governments to distribute these lands to private parties, in practice they are most often the object of illegal occupation, or "grilagem" as the practice is known in Brazil. Individuals occupy land in remote frontier regions, clear forest in order to establish possession, and then may sell or begin some economic activity (usually cattle ranching). Uncertain land tenure, with sporadic and inconsistent law enforcement in frontier regions, encourages deforestation as a means of establishing possession, while discouraging investment in longer-term, more sustainable land uses. 


\section{Box 2. The Searchinger study: the potential impact of biofuels on deforestation}

With macro-economic conditions and international food prices being the main drivers of deforestation, an increase in biofuel production is very likely to impact tropical deforestation. Searchinger recently used a global model for agricultural prices - the type of model used for WTO negotiations - to assess a scenario of biofuel subsidies in the United States. As 12.8 million hectares of corn are diverted from animal feed to ethanol in the US, prices for agricultural commodities rise, and farmers worldwide respond to this price signal by turning an additional 10 million hectares into cropland. It would thus take 167 years for greenhouse gas savings from biofuels to make up for emissions due to land conversion. This example of corn is especially striking as demand for meat and dairy products is not very elastic to price: a $5 \%$ increase in meat retail price only leads to a $0.9 \%$ decrease in the overall demand for meat. This means that corn fields diverted from cattle feed to biofuels production are almost replaced one to one by new fields (actually 10 to 12.8). Biofuels made out of sugarcane may have a much lower impact as the transformation process from sugarcane to ethanol is much more efficient.

Eventually, the impact of biofuels must be assessed on a case-by-case basis. Depending on crop yields, and the type of ecosystem converted for biofuel production, it may take shorter or longer to "pay back" emissions from land conversion: oil palm grown in grasslands may take only five to ten years to offset emissions it caused. But oil palm grown in peat forests takes nearly 700 years to make up for its emissions. In general, establishing biofuel feedstock in tropical forests - even degraded forests - requires decades to centuries to pay back emissions from conversion.

\section{Forests in the Existing Tools to Fight Climate Change}

\section{A. History of the issue at the UN}

Building upon the willingness gathered at the Earth Summit of Rio in 1992, most members of the UN signed the United Nations Framework Convention on Climate Change (UNFCCC) in 1994. Among other rules, the UNFCCC mandates that countries meet every year at the ministerial level to further the objective of the convention, namely to "prevent dangerous anthropogenic interference with the climate system". Of these yearly meetings or Conferences of the Parties (COPs), the most famous is COP 3 , which took place in Kyoto in December 1997 and was concluded by the signature of the eponymous Protocol. Regarding the issue of deforestation, four key dates paved the way to the current momentum on the issue:

December 2001, Marrakesh. The Conference fixes the rules for project mechanisms that can be implemented in developing countries. These rules allow for reforestation projects, but avoided deforestation is excluded. The main reason invoked is "leakage," namely the risk that forest protection may only displace deforestation to outside the protected areas.

December 2003, Milan. The Conference adopts the detailed rules governing reforestation projects. These projects are allowed to generate temporary credits - credits that need to be replaced every 5-30 years and their use for Kyoto compliance is limited to $1 \%$ of a country's target. On the deforestation front, a group of Brazilian and international scientists present the concept of "compensated reductions," proposing that tropical countries which reduce their national deforestation rate below an historical baseline should receive market credits.

December 2005, Montreal. Papua New Guinea, on behalf of the recently founded Coalition for Rainforest Nations, uses the compensated reductions approach to put deforestation on the official agenda. Because this approach resolves the "leakage" issue, the conference agrees to adopt a negotiation mandate on REDD which calls for funding of several workshops and for reaching a decision by December 2007.

December 2007, Bali. The Conference adopts a "road map" to negotiate a treaty that will replace the Kyoto Protocol due to expire in 2012. The road map lists REDD as one of the mechanisms to be included in this future treaty. This means that some kind of link between REDD and the international carbon market 
is likely to be created. The Conference also calls on countries and "relevant organizations and stakeholders" to undertake "demonstration activities" that will feed negotiations on the detailed rules of the future REDD mechanism. One of such "relevant organization" is the World Bank whose new Forest Carbon Partnership Facility should spur pilot REDD programs in the near future (see Box 3). In terms of resources, an important commitment also made in Bali is that of Norway, who pledged to spend 1.8 billion euros on REDD initiatives over five years.

\section{B. The close link between EU ETS and the price of forestry credits}

The case of forestry projects within the Clean Development Mechanism (CDM) illustrates the importance of demand in the success of project-based schemes in carbon finance. In 2007, forestry projects represented only $0.1 \%$ of CDM supply and the resulting credits traded around $2-3 € / \mathrm{tCO}_{2} \mathrm{e}$, that is $65-80 \%$ less than other CDM credits. Different factors can explain this failure to make a dent in the CDM market, such as the temporary nature of forestry credits or the 2-year delay in the publication of UNFCCC rules compared to other project types. But the exclusion of forestry credits from the European Union Emission Trading Scheme (EU ETS) probably provides the key explanation: without access to this major source of demand, forestry credits cannot fetch the same price as other credit types.

The review of the European Directive setting the rules for the European market from 2013 to 2020 is currently underway, and several European politicians have proposed to include a provision on REDD. The current draft directive will be debated during the second semester of 2008 and an agreement is expected at the beginning of 2009.

\section{Deforestation remains restricted to funds and the voluntary carbon market}

The Kyoto Protocol has created carbon finance, that is a demand for GHG emissions reductions. But the protocol has yet to establish a mechanism to link this source of reward to programs and projects aimed at reducing emissions from deforestation. Currently, the only outlet for the climate assets of REDD initiatives is the voluntary market for carbon offsets: the emissions reduced by these initiatives are funded by individuals or companies who voluntarily wish to offset their GHG emissions. A pioneer example has been the Noel Kempff Climate Action project in Bolivia: in 1997, the American Electric Power Company (AEP), Beyond Petroleum (BP), Pacificorp, and The Nature Conservancy (TNC) invested about 6.5 million euros in the extension of the Noel Kempff national park. A project design document, including methodologies for baselines for selective logging and deforestation, estimated the emissions reductions at about $1 \mathrm{MtCO}_{2} \mathrm{e}$ up to 2002. This document was subsequently verified by Société Générale de Surveillance (SGS). This endowed the Bolivian government and its corporate partners with 1 million Verified Emission Reductions (VERs) to sell on the voluntary market.

The World Bank's BioCarbon Fund, though mainly focused on reforestation projects, has signed a purchase agreement with three projects - located in Madagascar, Columbia, and Honduras - that include a REDD component. To quantify the VERs generated by these projects, the Bank will soon publish the first complete REDD methodology, built on the same model as MDP methodologies.

As the issue of deforestation is again making headlines in the context of international climate negotiations, avoided deforestation projects seem to be getting more and more popular on the voluntary carbon market. However, this market has evolved since 1997 and customers now demand more uniform quality standards for offset projects. That is why we currently see many voluntary REDD projects being developed under the CCBS and VCS certification schemes ${ }^{6}$ : since the United Nations climate conference of Bali officially included avoiding deforestation in the range of tools to be used in the post-Kyoto framework, the share of CCBS projects including a REDD component has tripled.

\footnotetext{
${ }^{6}$ The Climate Community and Biodiversity Standard (CCBS) and the VCS (Voluntary Carbon Standards) are two certification schemes aimed at providing some degree of quality assurance on the offset credits exchanged on the voluntary market. These two schemes are not mutually exclusive and most projects seeking CCBS certification are indeed simultaneously seeking VCS certification. For more details on the Voluntary Market, see Issue ${ }^{\circ} 11$ of the Climate Report series.
} 
Table 2 - REDD funds and grants launched in the wake of the Bali decision

Name

Contributors Amount (M€)

Aims

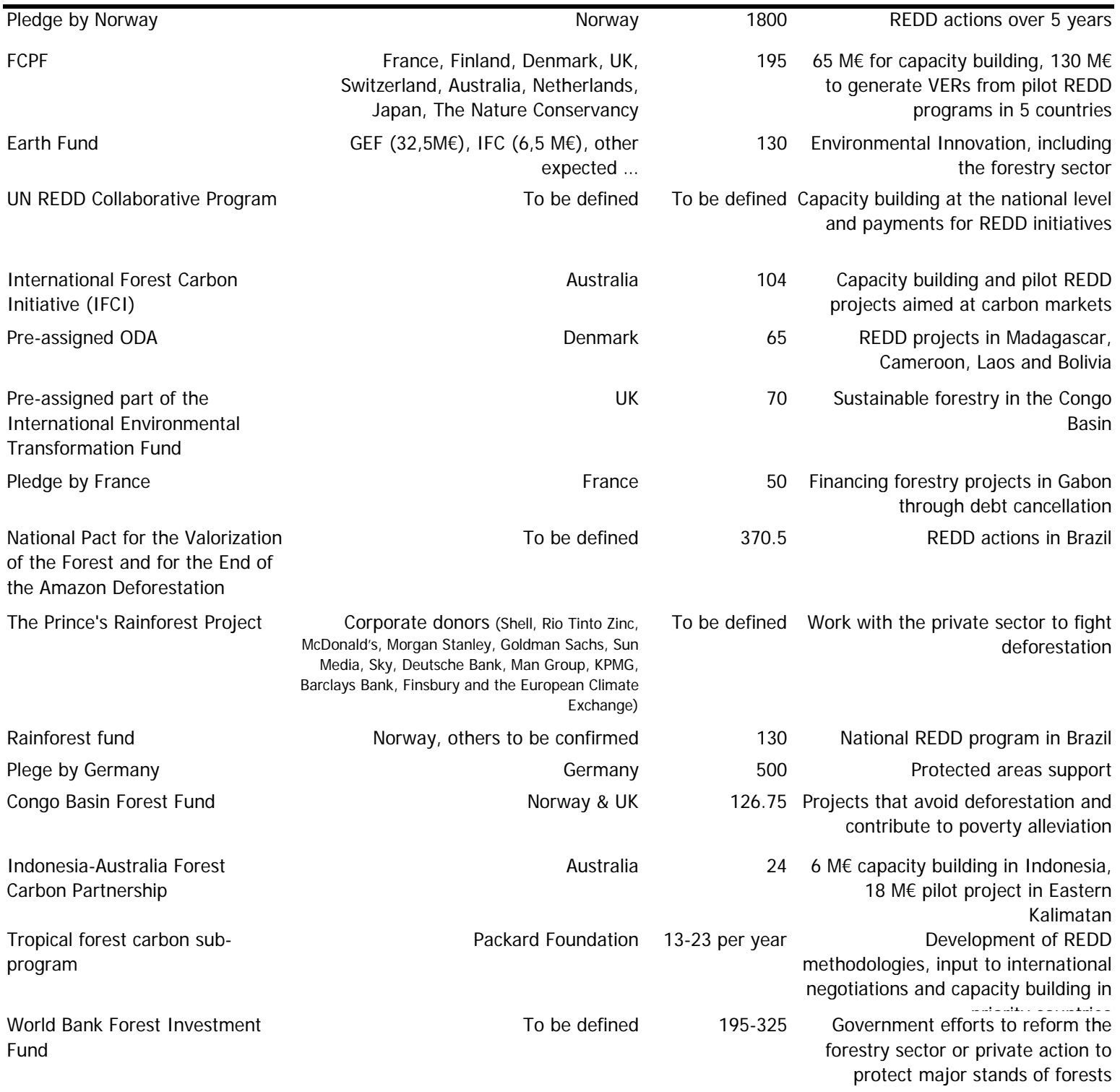

Note: Some of these initiatives are not entirely dedicated to REDD (eg. Earth Fund) and some may overlap (eg. part of Norway's pledge may end up in the FCPF and Brazil's Rainforest Fund).

Source: Mission Climat of Caisse des Dépôts.

The Bali decision was also followed by a flurry of REDD funds or grants (see Table 2). Although some of these grants are not directly linked with the carbon market, at least one of them aims to generate carbon credits: the World Bank's Forest Carbon Partnership Facility (FCPF, see Box 3). Brazil's Rainforest Fund as currently configured is attempting to attract public or private donations as compensation for deforestation reductions from 2003 - 2007 but would issue only non-tradable emissions reductions "diplomas", not eligible for offsetting purposes. 


\section{Box 3. The World Bank's Forest Carbon Partnership Facility}

In December 2007, during the UN climate conference in Bali, the World Bank officially launched a new facility aimed at stimulating pilot programs that convert successful fight against deforestation into tradable carbon credits. To that end, the facility is divided in two windows:

The first window, with a fundraising objective of 75 million euros, is devoted to capacity building. Its intent is to help countries with monitoring issues, so that they may be able to host pilot carbon programs. As of July 2008, the FCPF has selected 14 countries to receive 1.2 million euros each for this purpose. Other applicants are being considered.

The second window, which aims at raising 130 million euros, will be the part that contracts with countries or project developers and buys the carbon credits. On the supply side, the Facility will pick only a handful of host countries in order to concentrate financial resources. On the demand side, investors to this second window will receive carbon credits tradable either on voluntary or compliance markets, depending on the result of international negotiations on the issue.

\section{Measurement and Monitoring Stakes for Carbon Related Payments}

$\mathrm{Be}$ it donations or market credits, financial resources to fight deforestation now with increasingly stringent demands that they be put to efficient use. Measuring the amount of carbon lost through deforestation is therefore a first necessary step on the way to rewarding avoided deforestation with carbon-related payments. As mentioned earlier, this requires the overlaying of a map representing land-use change on another layer representing the carbon content of existing land uses.

\section{A. Remote sensing techniques are operational to map land-use changes}

The FAO has long been collecting data on forest cover from national forest services and experts. This data set provides estimates of forest cover change on a per-country basis since at least 1980, but for more than a third of countries, it relies on "expert assessment" or extrapolation from old surveys. While it may be interesting for general trends, this data set is highly variable in quality and too coarse for the monitoring of carbon-related payments.

For that purpose, remote sensing methods are more likely to be used. To detect deforestation, satellites act as cameras and the pictures they take are then automatically analyzed so that each pixel is classified as forest or non-forest. With high resolution satellites such as SPOT, LANDSAT and CBERS, this method reaches an accuracy of $80-95 \%$ in the resulting forest cover maps. It is thus possible to detect deforestation events larger than 0.5-1 hectare within 3-5 days, or events larger than 0.05 hectare within a month, provided that the deforested spot is not masked by clouds. The cost of such monitoring is around $0.02 € / \mathrm{km}^{2}$.

This type of monitoring capacity is increasingly used by countries for real-time monitoring of deforestation: based on medium resolution satellite imagery (MODIS), the Brazilian ministry of the Environment (INPE) publishes monthly all deforestation events larger than 6.25 hectares on its website. Together with Brazil, India has already developed regular forest surveys based on remote sensing data, and Bolivia, Peru, and Indonesia are developing similar monitoring programs. In the case of Brazil, the margin of error for the national deforestation rate measured from LANDSAT data is as little as $4 \%$. 
Figure 13 - Real-time deforestation monitoring online

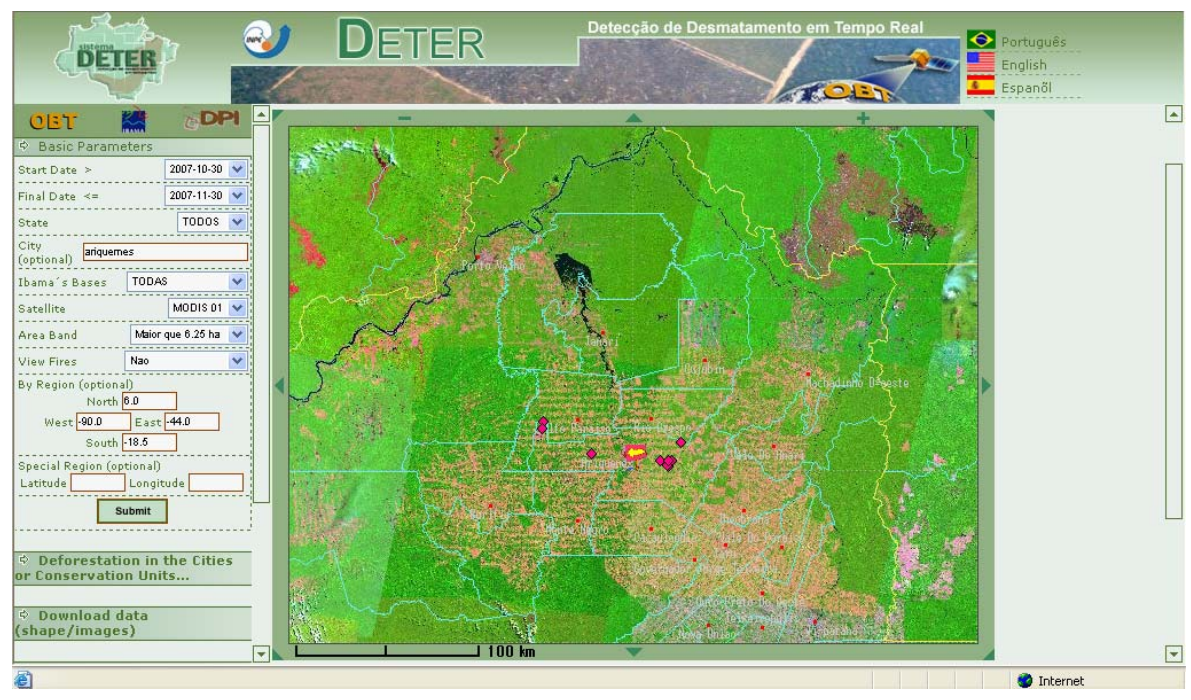

On the website of the Brazilian ministry of the Environment, monthly updates on deforestation events are available since 2002. This example shows deforestation events in the area around Ariquemes, in the Brazilian state of Rondhônia. The pink spots indicate deforestation events larger than 6.25 hectares that occurred in November 2007.

Source: INPE.

Mapping forest degradation is more challenging as the contrast between intact forests and degraded forests is more subtle than between forests and non-forests. Nevertheless, several techniques have recently emerged with promising results. Based on high resolution satellite images, Asner managed to map forest degradation in the Brazilian Amazon with a $14 \%$ uncertainty on the total degraded area. Similarly, Laporte and Brown have also successfully mapped selective logging in parts of the Congo Basin, respectively using satellite imagery or aerial photographs.

\section{B. Mapping carbon stocks remains a challenging exercise}

Mapping carbon stocks is fairly straightforward, at least if it is restricted to above-ground biomass: there is a good correspondence between carbon stocks and tree volumes commonly measured by foresters through field inventories. Forest carbon inventories are however time-consuming and labour intensive, and thus expensive to carry out at a large scale. When large scale estimates are needed (as would be the case for carbon-related payments for avoided deforestation), the most common method has been to define a set of forest types and then add up the respective areas of each forest type weighted by its average carbon content. As forest carbon contents vary within such defined forest types, the estimates derived by older large-scale studies were subject to substantial uncertainty. Comparing 7 older studies that used this technique to estimate forest biomass in the Brazilian Amazon, Houghton found a variation of a factor two, from 143 to 340 billion tons of $\mathrm{CO}_{2} \mathrm{e}$. Pan-tropical estimates for the 1980s and 1990s also have high uncertainties, because they covered very large, complex regions without benefit of more recent remote sensing information such as MODIS or globally compiled LANDSAT data.

New methodologies are reducing the uncertainties of measuring forest biomass significantly. Saatchi used a method based on remote sensing metrics to refine forest type classification and managed to determine the spatial distribution of above-ground live biomass into seven biomass classes with more than $80 \%$ accuracy. Total forest carbon estimates for the Amazon basin ranged between 280 and $350 \mathrm{GtCO}_{2} \mathrm{e}$, with an average of $315 \mathrm{GtCO}_{2} \mathrm{e}$.

The recently published figures on biomass changes in French Guyana show another example of successful combination of ground inventories and remote sensing. In compliance with IPCC Guidelines, the National Forest Inventory (NFI) estimated emissions from deforestation in French Guyana at 3.5 $\mathrm{MtCO}_{2} \mathrm{e}$ in 2006. 


\section{Upcoming technological improvements}

New developments will further reduce uncertainties and lower costs in the near future:

- $\quad$ The PALSAR radar imaging sensor on Japan's Advanced Land Observation Satellite (ALOS) collects high resolution, cloud-free images day or night. The ALOS mission data acquisition strategy is designed to systematically map all of the Earth's major land masses at least three times a year, at 10m, 20m and 100m resolutions. The Woods Hole Research Center, Amazon Institute for Environmental Research and Japan Space Agency (JAXA) are investigating the use of PALSAR for direct measurement of forest biomass from space.

- $\quad$ Brazil's National Space Research Agency has accurately measured Amazon deforestation for nearly thirty years and recently launched a second China - Brazil Earth Resources Satellite (CBERS). Brazil is extending its coverage to all of the world's tropical forests and has committed to make the data and software to interpret it available for free on the internet. It has also proposed to create a tropical forest remote sensing center to train tropical country scientists in monitoring and measurement.

Freely available high resolution remote sensing data, from a developing country consortium, in conjunction with a south-south training program will greatly improve the prospects for REDD. Brazil's policy of transparency is contributing greatly to improving deforestation analysis, as state and federal agencies, NGOs and researchers critically debate the data. Full transparency and public availability of data will be even more important for the credibility of REDD than independent certification.

In a more distant future (5 to 10 years off), new technologies could also improve accuracy:

- $\quad$ Promising experiments have been carried on with radar-type of sensors to estimate above-ground volumes (LiDAR and laser).

- $\quad$ The European Space Agency (ESA) is considering the launch of a satellite to measure forest biomass without saturation (band $P$ radar).

- Combining forest growth models with remote sensing data could also provide more accurate estimates of forest carbon.

\section{Non-permanence}

When the methane emitted by a landfill has been captured and flared during a year, the atmosphere has "gained" from the avoidance of a year's worth of methane emissions, even if the project collapses afterwards. However, when subsidized fertilizers preserve a patch of forest since farmers can produce more with less land, the atmosphere is only holding its breath: if the project collapses, the forest will be cut and the corresponding carbon will only have waited a little longer before being emitted. This is the risk of non-permanence.

The temporary nature of the existing Kyoto credits for reforestation were based on the idea that the credits generated by forestry projects are only valid for a given number of years, after which they must be replaced by other credits. Those who buy temporary credits are thus betting that credit prices will fall in the future: their anticipation is that waiting today and buying a permanent credit tomorrow are cheaper than buying a permanent credit today. So far, such buyers have been very few: indeed, most market actors expect carbon prices to rise in the future.

This absence of demand for temporary credits may explain the new avenues explored by the voluntary market for forestry credits: many certification schemes such as the Voluntary Carbon Standard, Carbon fix, or Greenhouse Friendly developed insurance schemes in order to produce permanent forestry credits. The Voluntary Carbon Standard for example withholds part of the emissions reductions from each forestry project so that the rest can be sold as permanent credits. Should a project collapse and its emissions reductions be only temporary, a corresponding amount of "insurance credits" are debited from the common insurance pool to replace the credits of the deficient project. 
Such insurance systems only work for a given period of time as few entities can convincingly guarantee that a specific patch will remain forested for eternity. The Voluntary Carbon Standard thus put at 70 years the limit of its guarantee. This assumes that in 70 years, pressure on forests will be as low in tropical countries as it is now in industrialized countries, thus removing the threat that justified the avoided deforestation project. Insurance systems could also hold non-forestry allowances or offsets. These experiments on voluntary markets could be very relevant for international negotiations as the Coalition for Rainforest Nations has proposed that future REDD credits rely on insurance schemes operating at the national level.

Viewed at a national level however, non-permanence is a risk for all sectors in an international trading system: a country that reduces below its target in one period might opt out of the system in a later period and increase emissions. Insurance mechanisms and clear liability rules in case of reversals, or nonpermanence, will be needed for all sectors.

\section{E. Leakage}

Leakage is the risk that a project undertaken to reduce emissions somewhere may not lead to global reductions, but only to a displacement from where the project takes place to somewhere else on the planet. It can occur in all sectors: connecting solar panels to a national electricity grid may either replace fossil fuel plants (and thereby reduce emissions) or generate its own demand for electricity through greater availability (and thereby not affect national emissions). Introducing a carbon tax on steel producers in Europe may give them an incentive to develop cleaner technologies or to relocate to countries that do not have a carbon tax.

The same holds for deforestation: when the process is driven by market demand for agricultural commodities, halting deforestation somewhere may increase it elsewhere if the demand for these commodities is not quenched. As costs rise however, this replacement is never one to one. Depending on location and scale considered, estimates of leakage vary widely, between $2 \%$ and $95 \%$. Even when considering only leakage within national boundaries for a specific project in Bolivia, Sohngen and Brown produced a scope of estimates ranging from $2 \%$ to $42 \%$.

One step to guarantee carbon credits against leakage is to grant them at the national level. Thus, if a conservation project only displaces deforestation where the forest is not protected, the national rate of deforestation is not affected and credits are not issued. This solution satisfies the concerns of European negotiators on the question of leakage: it does not completely suppress the risk leakage which can still occur from one country to another, but it raises the bar as high as the Kyoto Protocol on the other emission sectors.

\section{Negotiation Box 1. National vs sub-national approach}

The question of leakage has long plagued the recognition of avoided deforestation as a relevant approach to the fight against climate change. In 2001, the risk of leakage at the project level was deemed too great to include REDD in the project-based mechanisms of the Kyoto Protocol. Later on, European negotiators acknowledged that the national approach, first put on the table by the Coalition for Rainforest Nations, lifted this obstacle. This ended the debate until 2007, when some South American parties argued that granting market credits for sub-national projects was a necessary first step before a national framework able to affect the national deforestation rate could be put in place. Whether the REDD mechanism is to reward project-level initiatives or reductions of the national rate of deforestation therefore remains a point of contention.

Another possibility would be to grant project credit, but within a national carbon accounting framework with an insurance fund. After a certain time (five years for example), the amount of credits issued would be added up, and if project credits exceeded actual reductions in the sector (e.g., the forestry sector), a "true up" could be effected by accessing the insurance fund to buy allowances, emissions reductions or offsets. The insurance fund could be financed by allowance auction revenues, a tax on projects, or other types of public-private partnership. 


\section{Brazilian Lessons: Money, Good Governance and Monitoring Technology Can Reduce DEFORESTATION}

Since REDD returned to the international arena in 2005, consensus has grown around the idea that achieving national level reductions in deforestation and forest degradation offers the greatest benefit to the atmosphere and should be the ultimate goal of REDD programs, even as substantial differences remain over the timing and scope of programs and over appropriate financial mechanisms. The questions of whether and how tropical countries can reduce national level deforestation, in what time frame, and how much emissions reduction can be achieved have thus become central. Brazil, as the largest tropical forest country in the world, with among the highest rates of deforestation, and at the same time the most advanced national programs for monitoring and reducing deforestation, is a key test case for the feasibility of emissions reductions in deforestation.

\section{A. Deforestation in Brazil}

The Brazilian Amazon still has 330 million hectares of forests, rainforests and drier "cerrado" forests, with carbon stocks of some $315 \pm 35$ billions tons of $\mathrm{CO}_{2}$ equivalent. Some 61.6 million hectares, or close to $20 \%$ of the region has been deforested since the 1970s, very largely along the so-called "Arc of Deforestation" (Figure 14). Average deforestation in the 1990s was 1.7 million hectares per year, equivalent to 732 million $\mathrm{tCO}_{2} \mathrm{e}$ in emissions. Under a business as usual trajectory modelled by SoaresFilho, expansion of the agricultural frontier will eliminate $40 \%$ of the remaining forests by 2050 , releasing $115 \pm 30 \mathrm{GtCO}_{2} \mathrm{e}$ into the atmosphere.

Brazil's capacity to monitor and measure deforestation is not at issue: to the contrary, Brazil has taken the lead in proposing to make high resolution satellite data available to other developing countries (Figure 13). Drivers of deforestation are relatively well understood, with $70 \%$ of all deforestation for mostly low-yield cattle pasture. Illegal occupation of public lands and illegal logging in the absence of sufficient governance capacity for consistent law enforcement in frontier regions further contribute to high deforestation.

Remote sensing analysis of long term historical trends in deforestation shows an explicit spatial relationship between road building, urban areas and settlements, existing deforestation and new deforestation. About $80 \%$ of all deforestation is concentrated within $50 \mathrm{~km}$ of roads, and $86 \%$ of new deforestation occurs within $25 \mathrm{~km}$ of existing deforestation. These well documented spatial relationships permit modelling of expected future deforestation with a high degree of confidence. Increased demand for agricultural commodities, particularly soy and beef brought deforestation to a peak of $27,000 \mathrm{~km}^{2}$ in 2003 , the second highest annual rate on record. Deforestation then declined steadily until early this year when it picked up again (Figure 10).

This decline undoubtedly occurred in large measure because of falling commodity prices and a stronger currency, consistent with preliminary indications of increases in early 2008 with rising soy prices. But the decline was also in part due to the federal government's deforestation action plan, including large-scale reserve creation and vigorous law enforcement efforts. Brazil has made enormous advances in the creation of new protected areas in frontier regions of the Amazon: between 2003 and 2008 Brazil created 148 new protected areas in the Amazon, covering 62.2 million hectares. Counting indigenous lands, strictprotection and sustainable use Conservation Units and military areas, Brazil's protected areas network amounts to some $43 \%$ of the Amazon region, or about half of the remaining Amazon forest. Some of these reserves have additional technical and financial support from the Amazon Region Protected Areas (ARPA) Program. The emissions reduced by the creation of new protected areas between 2003 and 2008 has been estimated at $282 \mathrm{MtCO}_{2} \mathrm{e} / \mathrm{year}$ by Soares-Filho, for an overall cost equivalent to a one-time 2.5 billion euros investment. A detailed analysis of this program is provided in part V.B. The other Brazilian initiatives, which have not been subject to such in-depth assessments, are summarized in part V.C. 


\section{B. Amazon Region Protected Areas}

The creation of protected areas - whether strict protection areas, indigenous lands, or sustainable use reserves - stops deforestation and fires, even in active frontier regions. This has been demonstrated using satellite data to compare $10 \mathrm{~km}-20 \mathrm{~km}$ buffer zones inside and outside of protected areas. Given the clear spatial relationship between roads, road paving, and existing deforestation on one hand, and new deforestation on the other, the creation of protected areas in active frontier regions in the Amazon avoids deforestation. "Leakage" may occur, displacing some of the avoided deforestation outside of protected area, but no studies have attempted to determine whether it in fact does or to quantify this supposed displacement of deforestation by protected areas.

\section{Avoided Deforestation and Amazon Protected Areas}

To quantify the impact of large-scale protected area creation from 2003-2008, Soares-Filho has used a spatially explicit economic model based on known interactions between deforestation and profitability of soy, logging and cattle ranching to project future deforestation under varying policy scenarios, including the presence or absence of protected areas and degree of effective protection. An initial projection of business-as-usual deforestation from 2008 - 2050 was made, assuming that none of the protected areas existed, in order to establish the level of threat to lands put under protection or planned from $2003-2008$ (Figure 14)

\section{Figure 14 - Level of threat of deforestation by 2050 for lands not already deforested by 2008}

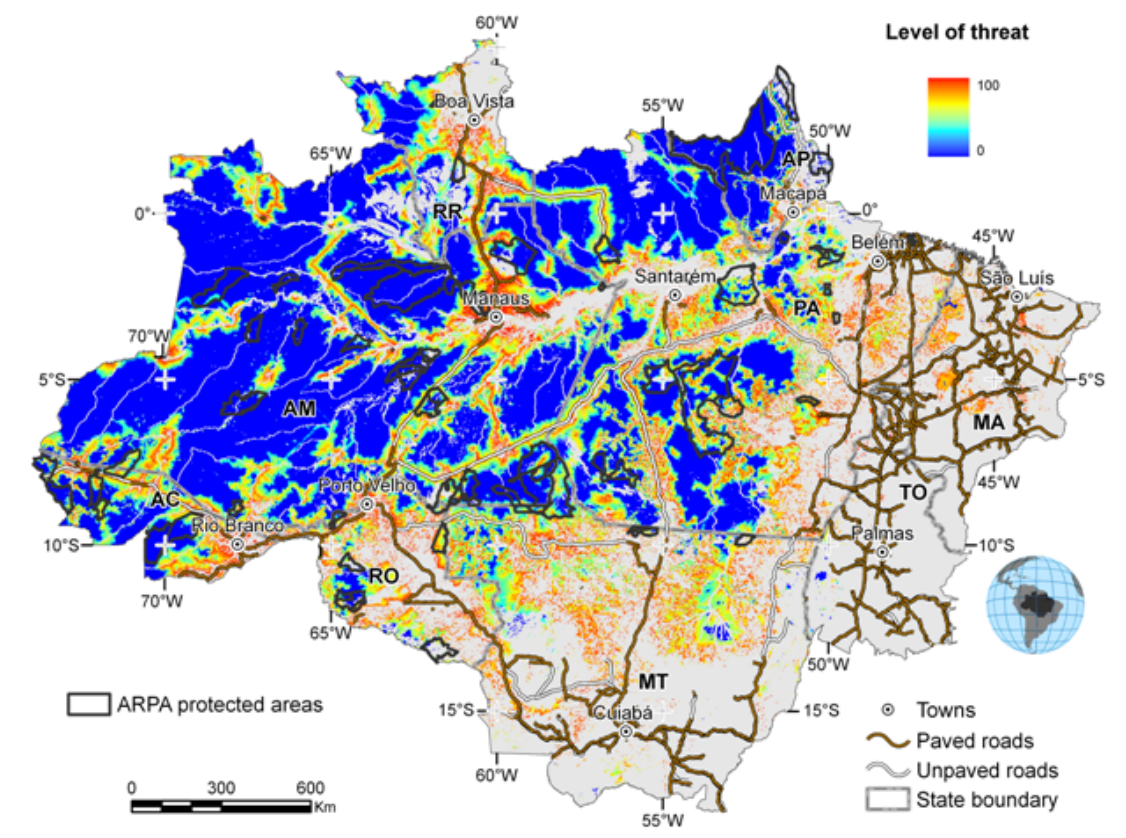

The scenario presented assumes no protected areas. Amazon Region Protected Areas Program (ARPA) areas outlined in black.

Source: Soares-Filho 2008.

The model then calculated the carbon stocks of the protected areas, superimposed carbon stocks on level of threat, and derived deforestation avoided by the protected areas (Figure 15). 
Figure 15 - Carbon Emissions Avoided by Protected Areas

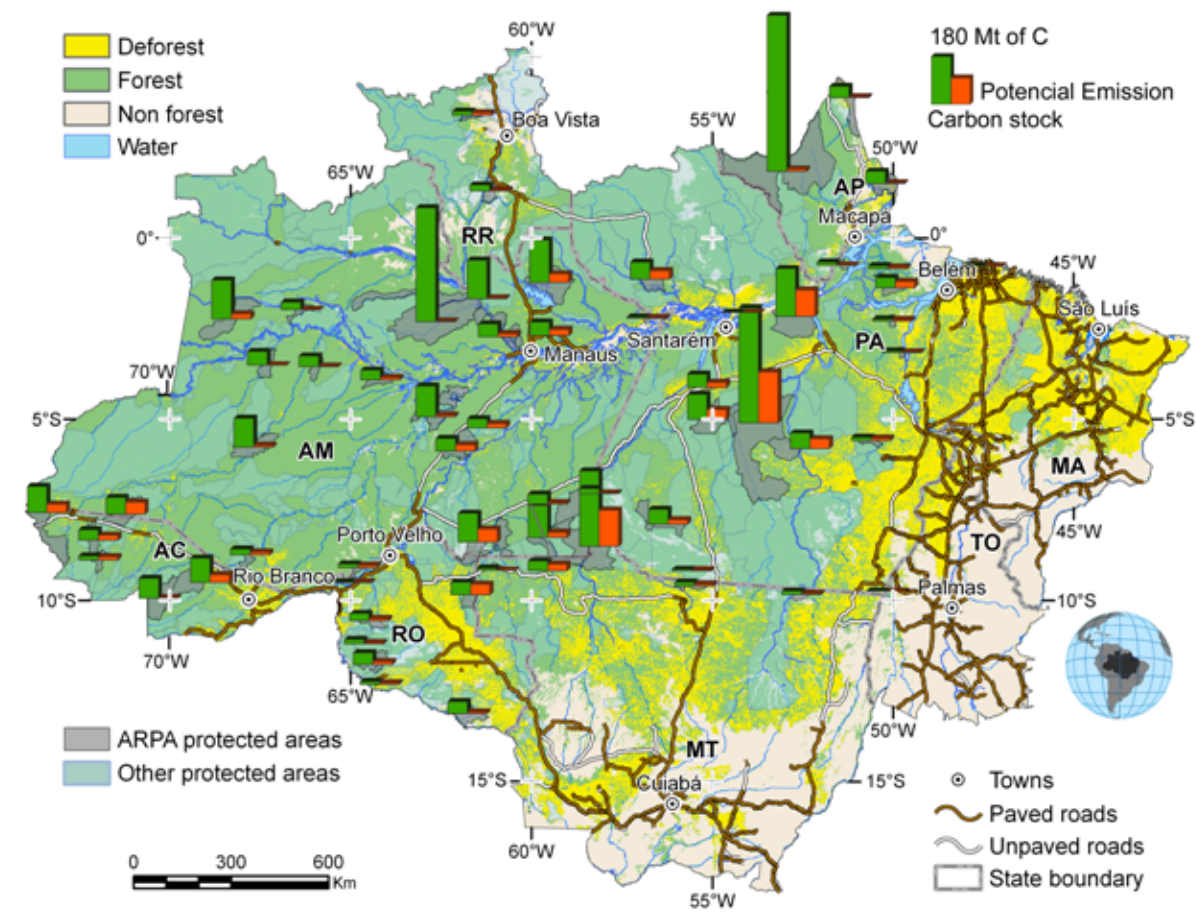

The amount of avoided emissions depends on the level of threat and the carbon stocks of the corresponding areas. Only deforestation emissions avoided by protected areas supported by the ARPA program are shown in this illustration. The ARPA supported areas account for about 12\% of emissions avoided by the areas created between 2003 and 2008.

Source: Soares-Filho 2008.

As shown by the figures above, the expansion of Brazil's protected areas network from $2003-2008$ alone will prevent the deforestation of an estimated $272000 \mathrm{~km}^{2}$ of forest, and thus the emission of some 12 billion tons $\mathrm{CO}_{2}$ by 2050, 282 million $\mathrm{t} \mathrm{CO}_{2}$ per year.

Protected Areas situated near expanding frontiers thus play an important role in avoiding carbon emissions. A key reason for that is that they were created in order to prevent deforestation, as well as for biodiversity protection and social benefits. Many were established in the context of the National Plan to Prevent and Combat Deforestation and located in high-deforestation, actively expanding frontier regions, as is the case of the areas with the highest potential emissions such as the Terra do Meio Ecological Station (the highest potential emissions illustrated).

It is important to note that the modelling exercise presented above, based on reductions below BAU deforestation, is not necessarily indicative of how a REDD compensation system would work. A system based on national level reductions below an historical baseline would have to allocate credit or provide compensation for the creation and maintenance of protected areas, but also for land owners who reduce deforestation, forest peoples and government agencies responsible for environmental law enforcement and services to forest peoples. Using an historical, rather than a business-as-usual baseline would reduce allowable compensation substantially. Were Brazil hypothetically to take a baseline of average annual

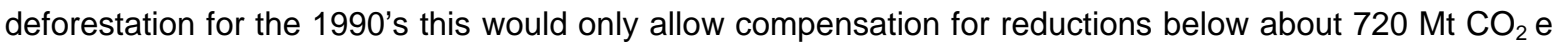
per year, or a maximum of $720 \mathrm{Mt} \mathrm{CO}_{2}$ e per year if deforestation were reduced to zero. Business as usual, in contrast, is projected at about 2.7 billion $\mathrm{tCO}_{2} \mathrm{e}$ per year up to 2050 .

\section{Amazon Protected Area Costs}

A rough estimate of the costs of these reductions may be derived from the Brazilian government's National Database of Protected Areas (Federative Republic of Brazil, 2008), and the Ministry of Environment's financial sustainability plan for the National System of Protected Areas. Assuming that investments are divided in accordance with the extent of protected areas, this comes to $4.5 € /$ ha in upfront costs, and about $2.9 € / \mathrm{ha}$ in annual costs. Since an endowment of $29 € /$ ha would at $10 \%$ interest produce a revenue stream of $2.9 €$, an initial investment of $33.8 € /$ ha, or 2.5 billion euros, would in 
principle cover projected costs of the Amazon protected areas. Even relatively low carbon prices (around $10 € / \mathrm{tCO}_{2} \mathrm{e}$ ), would quickly cover these costs, were Brazil to receive credit for deforestation avoided by Amazon protected areas.

These cost estimates are roughly consistent with preliminary estimates of the costs of implementing and maintaining the Amazonas state protected areas network. The Amazonas state Secretariat for Sustainable Development concludes that enforcing reserves extent in 2007 and creating proposed reserves would prevent emissions of some 310 million $\mathrm{MtCO}_{2} \mathrm{e}$ by 2050. Annual costs for maintenance of the state's protected areas network are about $2.3 € / h a$, in addition to up-front costs for expropriation of landholdings of 35 million euros. If this cost is distributed across the 17 million ha of the state's protected areas network and transformed into a one-time endowment, total costs for establishing and maintaining the protected area network come to about $28 € /$ ha, or 475 million euros. This plan for heightened protection of the state system of parks and reserves is only part of a state-level reduced deforestation program which also includes compensation for ecosystem services for forest-dwelling traditional communities, and compensation for opportunity costs of cattle ranching and logging. Overall, the government of Amazonas state estimates that the project could avoid 3.4 billion $\mathrm{tCO}_{2} \mathrm{e}$ by 2050 .

The actual costs of making a REDD system work would of course be higher than these. An effective REDD mechanism must at a minimum compensate legal landowners to forgo rights to deforest; forest peoples whose presence in indigenous territories and extractive reserves has guaranteed the protection of their forests, and government agencies responsible for environmental law enforcement and for providing services to forest peoples. However, comparing these estimated costs of protected area management with the potential business-as-usual deforestation emissions avoided by protected areas in frontier regions suggests that REDD can produce low cost emissions reductions in the near term. It also suggests that REDD compensation, even at modest carbon values, can produce sufficient resources to reduce deforestation.

\section{Other Brazilian Initiatives: National Plan to Combat and Prevent Deforestation, Satellite-based environmental licensing, and the Zero Deforestation Pact}

Brazil's large-scale expansion of the Amazon protected areas network was one aspect of a broader National Plan to Combat and Prevent Deforestation, formulated by the Environment Ministry in 2003. Launched in 2004, the plan focused on law enforcement, interventions in the land market, and interdicting deforestation as well as reserve creation. In a series of enforcement operations, Brazilian Environmental Institute (IBAMA) staff and Federal Police arrested and jailed over 400 people, including IBAMA and state environmental agency staff, for illegal logging, and issued fines in the hundreds of millions of reais. Licenses to log or deforest were suspended in the highest-deforestation zones, and National Institute for Colonization and Agrarian Reform (INCRA) ceased issuing the "CCIR" (Certificate of Registry of Rural Property), a document routinely issued to register land claims, but just as routinely used fraudulently as proof of ownership, for purposes of obtaining documentation to legalize or sell illegally occupied land. Since illegal occupation of public land is a major driver of deforestation in new frontiers, this measure aimed to slow illegal occupation and turnover of frontier land.

The National Plan adopted Mato Grosso state's Integrated System for Environmental Monitoring and Licensing (SIMLAM; http://monitoramento.sema.mt.gov.br/simlam/), an innovative use of remote sensing technology for deforestation control. The program requires land owners who want to deforest to present the state environmental agency a geo-referenced satellite image of their property, indicating the area they intend to clear as well as legally required protected areas (in the Amazon biome, $80 \%$ of all private holdings should be kept in forest, in addition to riparian forests, hill tops, and slopes steeper than $45 \%$ ). If, as is often the case, more than the legally permitted part of the property has been cleared, the landowner must present and begin to implement a plan for restoration of forests, or for acquiring other forest land to be kept in reserve. While only some 30\% of the landholdings in Mato Grosso have been registered, remote sensing monitoring of individual properties for compliance can lower enforcement costs while making enforcement of environmental law much more consistent. 
When Brazil's National Institute for Space Research (INPE) detected increasing deforestation in January and February of 2008 relative to the previous year, the Federal government adopted a series of new steps in an attempt to reverse the trend. Deforestation was prohibited in the 36 highest-deforestation counties, which were required to register $80 \%$ of their respective properties for satellite based environmental licensing in order to lift the ban. In addition, the National Monetary Council of the Central Bank issued a ruling requiring Amazon landowners to demonstrate compliance with environmental regulations in order to access official agriculture credit, prompting vocal protests from ranchers and soy planters, Mato Grosso governor and major soy planter Blairo Maggi in particular. Reportedly, however, a majority of Amazon state governors in a June meeting did not support Maggi's call for joint pressure on the federal government to rescind the measure, which went into effect July 1, 2008.

Amazon state governments and some private sector actors are apparently coming to regard deforestation as a problem not only for their public image, but for their future economic growth. In October 2007 a group of environmental NGOs, with the support of four Amazon state governments and the National Bank for Economic and Social Development (BNDES), launched a "Zero Deforestation Pact", outlining a plan to end Amazon deforestation over 7 years at a cost of a billion dollars per year. The pact, in contrast to Brazil's official position, calls for international carbon market finance as one among several funding sources (including the federal budget and bilateral and multilateral ODA).

None of these other pillars of Brazil's policy to control deforestation have been subject to ex-post assessments similar to that conducted on the effect of protected areas. The recent resignation of Marina Silva, the charismatic minister for the environment, has been interpreted by some as a sign of the low efficacy of these initiatives, yet several studies, in particular those by Fearnside and Chomitz showed local results from the licensing program in Mato Grosso despite a corruption scandal in 2005. Eventually, the success of these initiatives will be assessed through the long term rate of deforestation in the Amazon.

\section{How Could Carbon Markets Be Used?}

According to the OECD, about $1 \%$ of total Official Development Assistance (ODA) goes to the forestry sector. This amounted to an average 343 million euros per year between 2000 and 2005. It is about a hundred times less than the 41 billion euros of private investment in this sector in 2004 , or the 42 billion euros that the global carbon market was worth in 2007. In this context, two ideas quickly come to mind: increasing the part of the forest sector financing invested in conservation or sustainable logging, and attracting part of the carbon market funds to the forestry sector. Both ideas are based on exploiting the "climate assets" that standing trees represent. In other words, this means creating a link between carbon finance and REDD initiatives.

\section{A. The theoretical carbon value needed to avoid deforestation}

As for carbon sequestration options - such as changing forest management or agricultural practices assessing the costs of avoiding deforestation raises many methodological issues. These are partly due to the estimation of the counterfactual scenario, i.e. the evaluation of the benefits from exploiting deforested land. Indeed many activities underlying deforestation are informal and their economic outputs difficult to estimate: food production may be self-consumed, property rights may not be defined, etc. Prices on these informal markets (e.g. price of land) are often lacking. Global assessments are even more challenging since, as shown in part I.D, deforestation mechanisms mostly depend on local specificities of agriculture, forestry, poverty and transportation, which are difficult to extrapolate.

The scientific literature reports two methods for assessing the costs of avoided deforestation, depending on the scale of the analysis:

- A bottom-up analysis of local individual behaviours to assess the total economic benefits from deforestation, including timber harvesting, cattle ranching and agricultural activities. The mean cost of avoiding deforestation is then assessed as the revenue that local stakeholders can get from deforesting one hectare (opportunity cost). In order to provide policy-relevant information, some studies also add administrative costs for forest conservation, based on prior experiments. Results are generally shown in 
terms of discounted cumulated costs. Typically, this corresponds to the level of initial investment needed to cover all these costs for 30 years.

- Running global models of agriculture and forest markets to assess the global potential to avoid deforestation with different levels of carbon price. These models generally rely on regional aggregate parameters - for land, timber and/or food - and involve either optimizing the use of land or simply in simulating the behaviour of representative agents on land, agricultural products and timber markets.

\section{Bottom-up approaches point to low costs in the short term}

The bottom-up approach is more likely to provide robust estimates of the real net returns from small-scale deforestation. These estimates are often based on more detailed knowledge of local present motivations underlying deforestation, economic signals, and institutional constraints. The bottom-up approach can be very valuable for policy design, by helping to shape efficient instruments adapted to local conditions.

The main weakness of this kind of approach is its lack of comprehensiveness. Indeed it is not reliable to predict the cost of avoiding deforestation on a large scale. Large-scale actions against deforestation may create scarcity on the agricultural commodities that would have been produced by clearing land. Scarcity could in turn lead to price hikes that change local conditions and make past bottom-up studies outdated. Even if compensation for avoided deforestation leads to the intensification of production, this will likely entail higher input costs, leading to some increase in prices. Such intensification is probably feasible in the Amazon where low value extensive cattle ranching is rife. For other commodities intensification will be more challenging.

Our review of cost assessments for avoiding deforestation from a selection of existing bottom-up analysis is presented in Annex 2. Opportunity costs range from virtually zero (Rubber agroforestry in Indonesia, traditional pasture in Brazil) to $5.2 € / \mathrm{tCO}_{2} \mathrm{e}$ (in Ghana, where the study includes timber revenues). When compared to abatement costs for emissions from fossil fuels (over $10 € / t$ ), it suggests that avoiding deforestation - at least at the small scale relevant to opportunity costs analysis - may be among the cheapest options for reducing global GHG emissions. In addition, Grieg-Gran mentions that administrative costs of avoiding deforestation can range from 3 to $12 € /$ ha of initial investment, which is negligible compared to the opportunity costs reported above, since one hectare of protected forest is worth between 300 and 1,000 tonnes of $\mathrm{CO}_{2}$.

\section{Global models put the REDD mitigation potential around $3 \mathrm{GtCO}_{2} \mathrm{e} / y e a r$ by 2020}

Global modelling is a response to the issue of comprehensiveness. It weighs and measures the interactions between deforestation and the global pressure on land caused by increasing demand for food, biomass and wood. The counterpart of this comprehensiveness is a lower level of confidence on the representation of micro behavioural changes, including a general underestimation of institutional and economic barriers that could lower the potential for avoiding deforestation at a given carbon price.

The potentials for avoiding deforestation can be assessed at the global level and over longer time horizons (e.g. 2050, 2100). Results provide total amounts of avoided deforestation induced by various carbon price scenarios during the $21^{\text {st }}$ century. Interestingly, three different models (GTM, DIMA, and GCOMAP) have been used to test the effect of a permanent carbon price of $13 € / t \mathrm{CO}_{2} \mathrm{e}$, which is $30-50 \%$ less than current prices of carbon allowances on the European market. In response to this price signal, these global forestry and land-use models predict a reduction in deforestation emissions ranging from 1.6 $\mathrm{GtCO}_{2} /$ year to $4.3 \mathrm{GtCO}_{2} /$ year by 2030 . The latter figure would mean a virtual halt in tropical deforestation. These projections should nevertheless be taken with caution as these two models were designed for global forestry markets and only coarsely integrate the positive feedback of avoided deforestation on agricultural prices (through the rental price of forest lands). Further studies are expected to couple global forestry models to global agricultural models and yield more solid estimates.

An interesting finding is also that the theoretical carbon value that would completely stop deforestation is highly dependent on the region considered: in the simulations of Sathaye, it is $6.5 € / \mathrm{tCO}_{2} \mathrm{e}$ in Africa, 
$26 € / \mathrm{tCO}_{2} \mathrm{e}$ in South America and $50 € / \mathrm{tCO}_{2} \mathrm{e}$ in the rest of Asia. These variations stem from heterogeneous regional prices of timber and profitability rates of alternative land-uses. Timber prices are also critical to explain why bottom-up studies that often do not take into account revenues from harvesting are generally lower than the figures from global assessments.

\section{B. From theoretical opportunity costs to effective implementation: the low-hanging fruits of a tall tree}

Considering together local bottom-up analysis and global modelling results clearly highlights the difference of scale between the two approaches. Bottom-up analyses provide valuable information on the very low cost of avoiding some carbon release locally in the current social and economic context. For a projection to a further time horizon, one has to refer to global projections. They show that costs increase significantly when further efforts are required. The first carbon fruits of avoiding deforestation may be lowhanging, but large-scale actions mean climbing higher in the tree (Figure 16).

Figure 16 - Low-hanging fruits of a tall tree

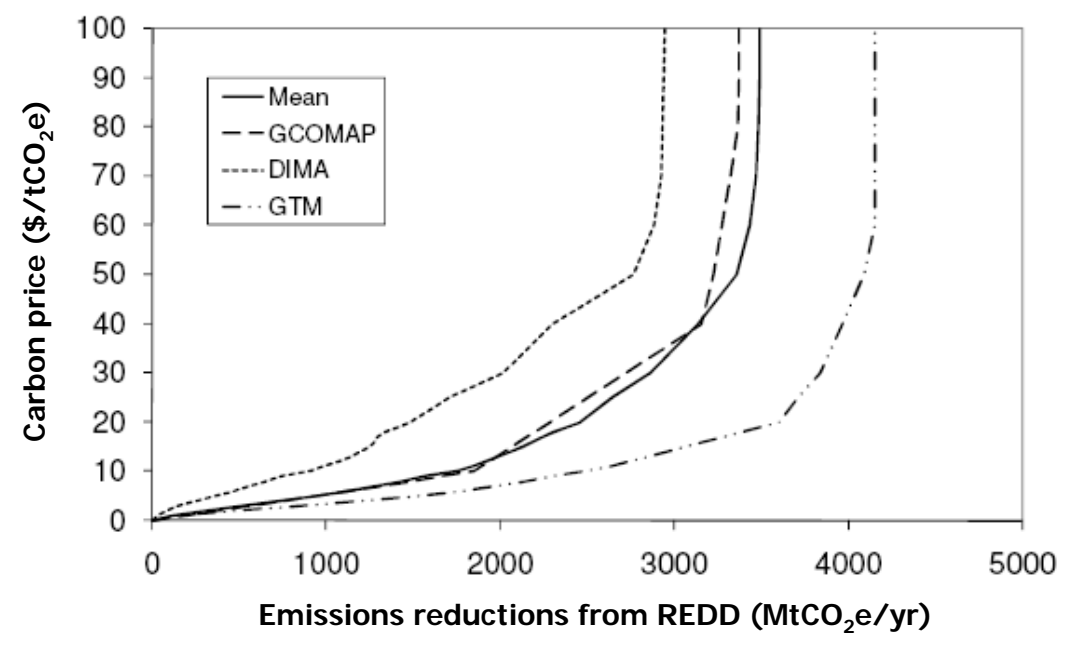

Global models estimates for REDD mitigation costs rise sharply once the first reductions have be achieved. This figure presents summarizes the findings of three global models: GCOMAP, DIMA, and GTM.

Source: Kindermann 2008.

Eventually, one must keep in mind that the achievement of such efforts not only depends on the level of the carbon price incentive but also strongly on implementation issues. Global models do not say anything about the feasibility of such generalized protection schemes and generalized payments for environmental services at a global level. On the contrary, they assume that economic agents optimize their income and directly receive the reward for their efforts. Actually reducing deforestation will be more complex and will require programs directed at specific local drivers of deforestation.

\section{Implementation issues make it hard to get over $1 \mathrm{GtCO}_{2} \mathrm{e} / y e a r$ in the short term}

Modelling scenarios are useful for looking at long-term, large-scale trends. To participate in a REDD mechanism, governments must be able to reliably monitor and measure emissions from deforestation, and consistently enforce environmental legislation such as protected areas. In almost all cases this will require massive investments that are not taken into account in global models. In the short term, most tropical countries thus face very substantial infrastructure and institutional barriers to participate in a REDD mechanism:

- Monitoring: currently, of high-deforestation nations, only Brazil regularly monitors and measures deforestation, and has formulated a national plan to combat deforestation. Building local capacity for monitoring a measuring deforestation on national levels will take not months but years. 
- Governance: Governance capacity varies widely. As the World Bank's recent forays in governance reform suggest, it is not necessarily susceptible to change in the near term, even when funds are available. Signals from northern governments and companies that reductions in deforestation will be rewarded may stimulate better forest governance, but this is not a foregone conclusion.

- $\quad$ Social capital: The importance of social capital for REDD is often overlooked. Countries that intend to establish transparent, credible REDD programs must have sufficiently developed civil society organizations or other mechanisms. It permits successful negotiations among the sectors of the society that must participate in REDD design and share benefits if it is to work. Brazil for example has included representative forest people's social movements in the effective negotiations for the implementation of a REDD program. On the contrary indigenous peoples' organizations in Indonesia have little and largely negative experience of negotiating with government, and a long history of acute conflicts with logging and oil palm concessionaires on what they regard as community lands. Many oppose REDD in principle since they see international funding of any kind for the government as more likely to harm than benefit them. It is not realistic to assume that a credible, let alone effective, REDD program could emerge from these circumstances in the short term.

No investor or funder will want to commit significant resources to programs that are environmentally dubious or liable to result in social conflict. The price for REDD credits will therefore reflect the risk profile of the country where the project is implemented: Sathaye concludes that the cheapest REDD credits would come from tropical Africa -- with the least governance capacity among tropical regions, chronic conflicts and fragile civil society organizations. It illustrates the risk of projecting REDD credits supply on the basis of price signals alone. Thus, neither bottom-up or top-down analyses of the opportunity costs of avoiding deforestation take into consideration all of the costs of reducing deforestation.

An optimistic assessment would be that most tropical countries could be ready to participate in nationallevel REDD in 10 to 12 years. Most of the initial REDD credits supply (for the next decade) can realistically be expected to come from Brazil, and some smaller Latin American countries. If we consider only REDD from reduced national deforestation compared to historical baselines, and assume that Brazil could eliminate deforestation over ten years, supply could gradually increase to 1 billion tCO $\mathrm{C}_{2} \mathrm{e}$ per year over the decade. This is far less than the average 3 billion $\mathrm{tCO}_{2} \mathrm{e}$ per year projected by global models.

\section{Who benefits?}

Avoiding deforestation completely in the long term, in order to bring a significant contribution to climate change mitigation, appears to be possible for carbon prices that are currently acceptable in the energy sector (e.g. 20 to $30 € / \mathrm{tCO}_{2}$ ). Nevertheless, paying to avoid the 3 billion tons of $\mathrm{CO}_{2}$ released each year from deforestation through carbon markets would nevertheless require enormous money transfers. If these avoided emissions are traded as carbon credits, they will sell at the price set by carbon markets. For a 20 euros carbon price, the money transfer would thus reach 60 billion euros per year. A fund could in theory require a lower transfer if it was able to discriminate between the low-hanging and high-hanging reductions, and set their reward accordingly. The governance of such a discriminating fund would be challenging, both in terms of technical feasibility and of political acceptability.

Apart from the question of the willingness of countries to pay for reduced deforestation, the question is how the money could be redistributed. The recipients of financial incentives to reduce deforestation will probably vary from case to case: if the REDD mechanism awards credits for reductions of the national rate of deforestation, the state will probably take a share. But to reduce the risks of non-delivery, foreign investors will demand a contract that insures that money and liability are transferred to the stakeholders who can actually affect the national deforestation rate: planning authorities if securing land tenure looks promising, farmers associations if intensifying agriculture is a potential solution, micro-credit schemes if developing new economic activities can decrease pressure on forests, etc ...

One important lesson that Wunder draws from the experience of payments for ecosystem services projects is that payment recipients must be carefully defined through a case-specific analysis. He cites the example of the buffer zone of Amboro National Park in Bolivia, where a $4.5 € /$ ha per year compensation was offered to farmers who engaged in conservation. As the agricultural potential of land varied greatly in 
this hilly landscape, the scheme proved to be too coarsely defined: the only forest plots which were enrolled in the system were those with such a low potential that they would have been preserved anyway. The possibility that some of the stakeholders targeted by REDD incentives turn out to have no impact on deforestation is another reason why global models or opportunity costs studies may underestimate the costs of REDD. Wunder identifies key stakeholders as those whose site-specific claims (ownership, the use rights, customary land rights, ...) make them bear some opportunity cost for conservation, and at the same time enable them to prevent third-party access to the land.

\section{An effective price signal: how can REDD be linked to carbon markets?}

\section{The three options to tap carbon markets: tax, auctions, and tradable credits}

The idea of tapping carbon markets to finance reductions in emissions from deforestation has occurred to many. Three main proposals have been put forward concerning the exact type of link to establish between REDD and carbon markets: a tax, the use of auctions revenues, and the creation of tradable REDD credits. Each of these proposals has its proponents in the international arena (see negotiation box 2).

- Tax: the idea is to copy the model of the UN "Adaptation Fund". This fund is intended to finance the adaptation of developing countries to climate change by drawing its resources from the CDM market. For each CDM credit issued, the UN retains $2 \%$ of its sale value for the Adaptation Fund. A similar "REDD fund" could be created to reward REDD initiatives. Its content would be split between successful REDD initiatives, in proportion to the emissions reductions achieved by each initiative. This financing proposal would add another layer to the already high transaction costs associated with project-based mechanisms such as the CDM. Other "tax proposals" would rather draw their revenues from allowances, carbonintensive products and services, or from a broader carbon tax.

- Auctions: as the EU ETS matures, more and more allowances will be auctioned instead of being allocated for free. This will generate revenues that could be used to finance a "REDD fund". In essence, the idea to use auctions revenues is quite similar to the tax. A "REDD fund" would also be created to reward REDD initiatives. The difference is the segment of the carbon market used to create the fund: instead of tapping project-based mechanisms, this proposal would draw resources from allowances.

- Tradable credits: the third option is convert emissions reductions from REDD initiatives into carbon credits that can then be sold to industries or countries for compliance. This proposal differs from the others in two main ways. First, the size of demand differs: in the case of tradable credits, REDD initiatives compete for the whole demand for carbon markets whereas in the case of a fund, they compete for a preassigned share of it. From an investor's point of view, the larger the demand, the more reliable the return on investment. Too many REDD initiatives will sooner dilute rewards from a fund compared with from the market as a whole. Tradable credits are thus more likely to attract private investors than funds. Second, the supply of carbon credits in the market differs: in contrast to a fund approach, tradable REDD credits are added to the overall credit supply. The larger the credit supply, the lower the carbon price. From a regulator's point of view, this has both an upside and a downside. The upside is that it lowers compliance costs for developed countries. The downside is that too low a carbon price could result in less domestic reductions than aimed at by the European Commission. This balance between more means for REDD initiatives and the risk of market flooding will be discussed in part $\mathrm{E}$, by comparing two coupled "forestcarbon" models. 


\section{Negotiation Box 2. Market vs fund ... and the use of auctions revenues}

At the UN level, the question of how to tap the carbon markets to finance REDD initiatives revolves around the market vs fund dilemma. The Coalition for Rainforest Nations, which officially includes around fifteen tropical countries in Asia, Africa and Latin America, favours carbon credits, exchangeable on the international carbon market, while remaining opened to other solutions. Brazil would rather see the creation of a fund, financed either voluntarily by industrialized nations or by a tax on project-based mechanisms. In any case, it currently opposes the use of REDD initiatives by industrialized nations to meet their international commitments.

The market vs fund dilemma is for the moment a matter of potential suppliers. Potential consumers, such as the EU, have not yet expressed their preference. But even if the EU stays neutral in the international arena, it will greatly influence the future of REDD through its decision on the ETS rules for the post-2012 period.

\section{How many carbon euros are we talking about?}

Figure 17 - Estimates of potential carbon-related payments based on current ETS rules (2008-2012) and market conditions

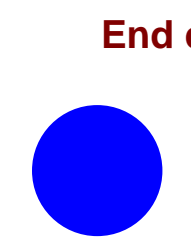

EU ETS

5.6 G€/year
Governments $2.6 \mathrm{G} € /$ year
Other private sector compliance $1.5 \mathrm{G} € /$ year
Voluntary market

$0.2 \mathrm{G} € /$ year
Auctions revenues

$(2008-2012)^{*}$

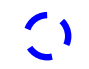

EU ETS

$1.3 \mathrm{G} € /$ year

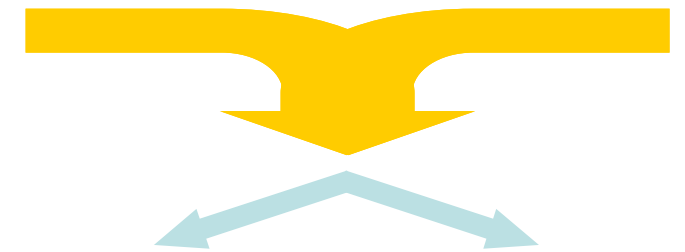

Tax-based fund

Tradable credits

Auctions revenues

*The end demand for imported credits is estimated based on given current rules and market conditions (eg. ETS quota of $280 \mathrm{MtCO}_{2} \mathrm{e} /$ year for CDM credits). Tons of $\mathrm{CO}_{2} \mathrm{e}$ are converted into euros assuming a $20 € / \mathrm{tCO}_{2}$ e price for both compliance project-based credits and auctionned allowances.

These estimates reflect the demand that REDD initiatives could tap into. It is impossible to draw projections from them as market conditions for the post-2012 period hinge on ETS rules that are yet to be defined, and on the outcome of US legislative proposals. Between 2008 and 2012, the end-demand for project-based carbon credits was estimated at around 10 billion euros per year. If auctioned allowances sell for $20 € / \mathrm{tCO}_{2} \mathrm{e}$, they would generate revenues around 1 billion euros per year. These estimates could be both the tax base of a potential REDD fund and the end-demand for potential REDD credits. Any of these three carbon-based payments would thus provide 10-20 times stronger supply of funds than the current level of Official Development Aid to the forestry sector (343 M€/year) ${ }^{7}$.

Source: Mission Climat from World Bank and OECD data.

\footnotetext{
${ }^{7}$ None of these incentives would entirely go to REDD initiatives: tradable credits would contend with other carbon credits, while competition among different constituencies for revenues from auctions or carbon taxes is inevitable. This is also true for ODA to the forestry sector, little of which currently goes to initiatives directly aimed at reducing deforestation.
} 
As illustrated in Figure 17, the EU ETS has been from now on the main source of demand for carbon credits in the world. It currently represents $57 \%$ of global end-demand for project-based credits with a total cap of 280 million $\mathrm{tCO}_{2} \mathrm{e}$ per year for 2008-2012. If international REDD credits already existed, an absence of restrictions for them within this cap would put the upper limit of demand at about 10 billion euros per year while a total exclusion of REDD credits from the ETS would restrict this upper limit to 4.4 billion euros per year. Leaving apart the potential rise of new sources of demand (North American compliance markets, voluntary markets), the future rules of the EU ETS for phase III (2013-2020) will determine the success of any system that is linked to carbon finance. The draft rules as they stand would entirely exclude REDD credits from the ETS. Yet, several European politicians have suggested part of the revenues of allowance auctions could be dedicated to REDD initiatives. In any case, the choices for future EU ETS design will either shape the demand for REDD tradable credits, or set the dimensions of the pool of credits to be auctioned or taxed by a tax-based fund.

\section{The hurdles from the supply side: a matter of baselines}

No matter which of the three approaches is used to tap carbon markets, reductions in deforestation rewarded by carbon-related payments will have to be determined against a baseline: during a given commitment period, emissions reductions below the baseline are to be rewarded. The principle of rewarding emissions reduction below an agreed-upon baseline is illustrated in Figure 18.

Figure 18 - The baseline determines how many reductions are to be rewarded

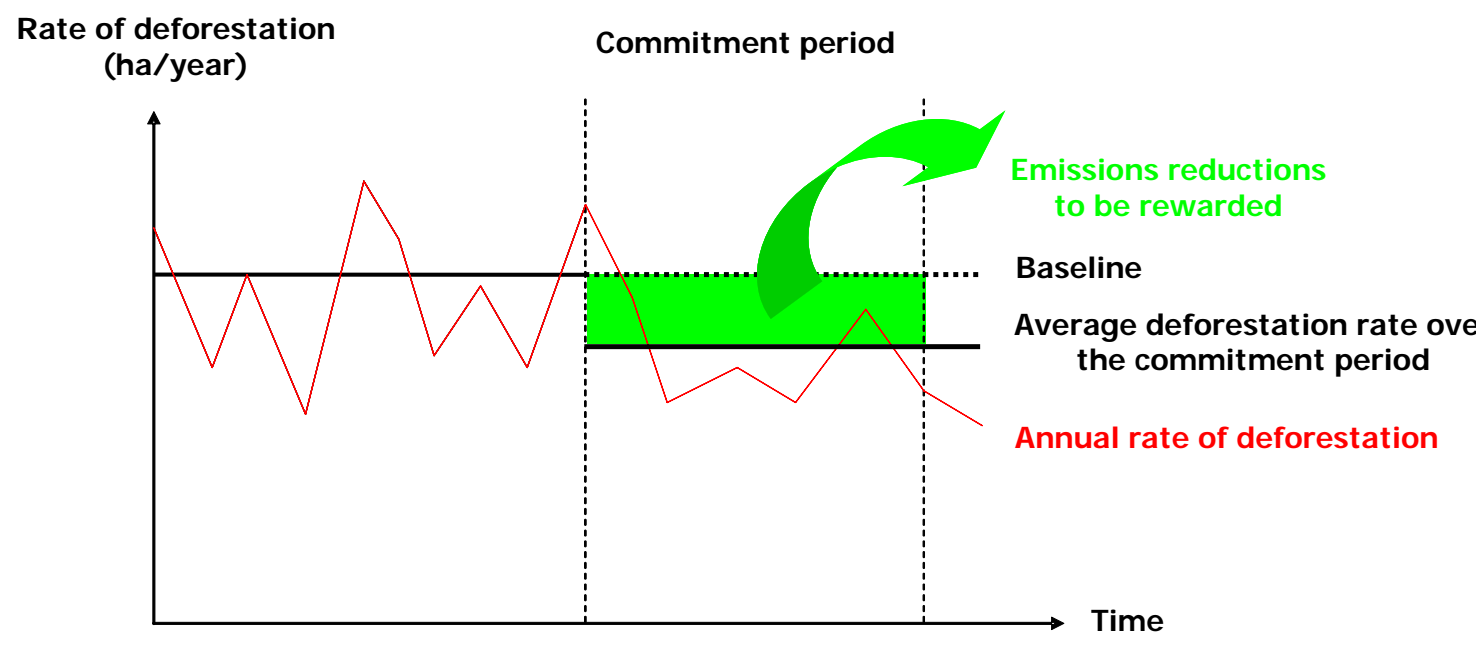

Carbon-related payments for the reduction of deforestation rely on a baseline: during a given commitment period, emissions reductions below the baseline are to be rewarded. In the example above, the baseline corresponds to the historical rate of deforestation before the commitment period.

Source: Mission Climat of Caisse des Dépôts.

For a project aiming at reducing deforestation locally, determining a deforestation baseline can be considered to be a technical issue that implies modelling deforestation drivers and monitoring the accuracy of the model in other areas unaffected by the project. But then again, rewarding emissions reductions at a local scale raises the issue of leakage.

For a program aiming at reducing deforestation nationally, determining a deforestation baseline can no longer be considered as purely a technical issue as there is no control area to check the validity of a deforestation model. In Kyoto, when time eventually came to get an agreement on the amount of reductions to be achieved by each country, the national objectives were set through political negotiations among governments. As argued by Pirard and Karsenty, the attribution of national deforestation baselines will probably follow on the same path. And the views of the negotiators may or may not be influenced by the projections of deforestation models (see negotiation box 3 ). 


\section{Negotiation Box 3. The choice of baseline: the question of "compensating conservation"}

It is too early for a real debate on the detailed national baselines to have already begun. However, given the differences in national deforestation rates between countries, the legitimacy of a historical baseline akin to those set by the Kyoto Protocol for industrialized nations has already been questioned. Countries whose historical deforestation rate is low and countries whose forest is currently growing are concerned that a REDD mechanism based on historical baselines will only reward countries which already have a high deforestation rate.

The Indian proposal in particular is articulated around "compensating conservation", by choosing a reference rate that rewards countries which have already taken steps to curb deforestation. The Coalition for Rainforest Nations backs this principle which will also benefit its Congo Basin members whose deforestation rate is still relatively low. Brazil also expressed its support to the proposal at the conference held in Accra in August 2008.

\section{E. The hurdles from the demand side: how much can be bought?}

In the case of a direct link with carbon markets, a key factor for the initial success of a REDD scheme will be its access to the European market. So far, European negotiators have been keen to support REDD initiatives at the international level, but the Commission is reluctant to open the gates of the ETS to REDD credits. Before doing so, it is indeed necessary to assess the amount of imported REDD credits that could arrive on the market. The risk to avoid is that this additional supply leads to a dramatic drop in carbon prices and deeply disrupts the young ETS.

Based on estimated costs of avoiding deforestation, the risk cannot be discarded. These estimates presented earlier are 10-20 times lower than current carbon prices, and the potential supply at current prices is could be twice as big as the total volume of existing credits on the ETS ${ }^{8}$. However, they do not account for two crucial feedbacks illustrated by Figure 19: the decreasing incentive to reduce deforestation as carbon prices drop due to an influx of REDD credits, and the increasing price of avoiding deforestation when agricultural prices rise due to lower deforestation.

\section{Figure 19 - Two crucial feedbacks to assess the impacts of REDD on carbon markets}

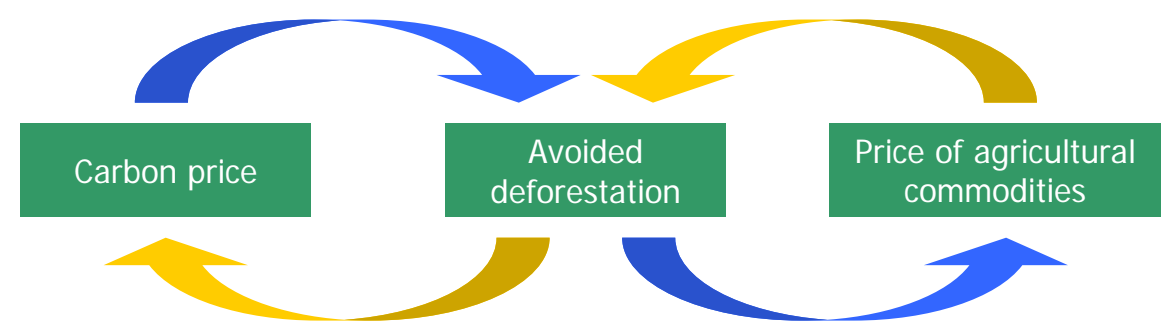

Source: Mission Climat of Caisse des Dépôts.

To date, only the first feedback on carbon prices has been quantitatively assessed. Through a dynamic model linking carbon markets to the forestry sector, Anger and Sathaye find a $40 \%$ decrease in the price of carbon, as REDD credits are allowed on the ETS without restriction on the top of CDM credits.

${ }^{8}$ Allocated ETS credits amount to 2,061 $\mathrm{GtCO}_{2} \mathrm{e} /$ year between 2008-2012 for the EU 27 + Norway and Liechtenstein. 
Table 3 - Anger and Sathaye's modelling assessment of the impact of REDD on the ETS

No imports allowed

Price of carbon $\left(€ / \mathrm{tCO}_{2} \mathrm{e}\right)^{*}$

Abatement within the ETS

( $\mathrm{MtCO}_{2} \mathrm{e} /$ year)

Imports of CDM credits on

the ETS $\left(\mathrm{MtCO}_{2} \mathrm{e} /\right.$ year)

Imports of REDD credits on

the ETS $\left(\mathrm{MtCO}_{2} \mathrm{e} /\right.$ year)

* Original prices in 2005 euro are increased by $23 \%$ to be comparable with the 0,65 euro/dollar exchange rate used for EDF's results

Allowing offset credits such as CDM on the ETS greatly diminishes the price of carbon from $55 € / t \mathrm{CO}_{2} \mathrm{e}$ to $9 € / t \mathrm{CO}_{2} e$. As 585 million tons of offsets enter in the market, the amount of domestic reductions decreases correspondingly. Interestingly however, allowing REDD credits on the top of CDM credits does not radically change the picture.

Source: Mission Climat of Caisse des Dépôts, adapted from Anger \& Sathaye.

Regarding the risk of flooding the ETS, this modelling exercise offers three interesting conclusions. These conclusions rely on the hypothesis that no cap is put on the use of credits which is for the moment far from being the case:

- Due to competition with CDM credits and feedback of credit imports on carbon prices, only about 300 million tons of avoided deforestation credits would enter the ETS. This is a tenth of the potential supply predicted by the same model for current carbon prices.

- The price signal on the ETS is greatly disrupted by the import of offset credits, thus leading to much fewer domestic reductions (about a third of the reductions occurring without offset credits).

- When both are allowed on the ETS, the influx of REDD credits is comparable to that of CDM credits with respectively 294 and 366 millions tons of $\mathrm{CO}_{2} \mathrm{e}$.

More recently, Environmental Defense Fund (EDF) also analysed the market impact of REDD, though using different assumptions. In their model, allowing forestry credits on all carbon markets reduces mitigation costs by $31 \%$ in 2020 , a result quite close to Anger and Sathaye's $40 \%$. The absolute mitigation costs however are quite different: EDF's projections are three times as high at around $16 € / \mathrm{tCO}_{2} \mathrm{e}$ if credits from all global forest carbon activities are allowed in the marketplace. This is largely because EDF assumes steeper reductions targets in developed countries: they assume the same objective for the EU but additional demand is created by the enactment of the Lieberman-Warner bill in the US ${ }^{9}$ and comparable efforts in other developed nations. Another factor is carbon credit banking, which is allowed in EDF's model: if actors are allowed to optimize abatement decisions over time by banking credits for future use, inclusion of REDD crediting - even under highly optimistic assumptions about the supply of REDD and forestry credits - would help to control compliance costs over the lifetime of the program, but also avoid dramatic price declines at any point in time. It will not itself substantially affect carbon prices in the long-term, which depend on global demand as determined by emissions reduction targets.

${ }^{9}$ The version of the Lieberman-Warner bill used in the model asks for a reduction of $19 \%$ of 2005 emissions by 2020 , and $70 \%$ by 2050 . 
Table 4 - Environmental Defense Fund's modelling assessment of the impact of REDD on carbon markets

\begin{tabular}{lrrr} 
& $\begin{array}{r}\text { CDM credits allowed for up to } 10 \% \\
\text { of commitments }\end{array}$ & $\begin{array}{r}\text { Same scenario for CDM credits }+ \\
\text { REDD credits without restriction }\end{array}$ & $\begin{array}{r}\text { Same scenario for CDM credits }+ \\
\text { forestry credits without restriction }\end{array}$ \\
\hline Price of carbon $(€ / \mathrm{tCO} e)$ & 23 & 20 & 16 \\
$\begin{array}{l}\text { Price of carbon }(€ / \mathrm{tCO} e) \\
\text { Forestry supply } x 2\end{array}$ & & 18 & 12 \\
Price of carbon $(€ / \mathrm{tCO} 2 \mathrm{e})$ & & 21 & 19
\end{tabular}

Forestry supply $/ 2$

Allowing REDD credits on international carbon markets only marginally diminishes the price of carbon (-14\%), while the impact of all forestry credits (including reforestation) is more important (-31\%). Alternative scenarios in which forest credit supply is both twice as large as well as half as large at each price level are considered to reflect uncertainties in forest carbon credit supply. Interestingly, these projections are not strongly sensitive to the underlying assumptions on the size of credit supply due to the influence of banking.

Source: Environmental Defense Fund (EDF).

In both models, even the more conservative scenarios - for example halving REDD credits supply in order to fuel an insurance scheme that caters for permanence - yield a carbon price lower than $20 € / \mathrm{tCO} \mathrm{O}_{2} \mathrm{e}$. According to most models, this price signal is not high enough to reach the $20 \%$ objective set by the Commission for emissions reductions within the EU. In order to reconcile imports of reductions with this objective, a careful balance has to be kept between supply and demand on the ETS. Several proposals have been put forward to this purpose:

- A quota limiting the number of imported project-based credits allowed on the market. According to the last draft directive of the Commission, this quota could be around 5\% of total emissions for CDM credits if a binding international agreement is reached for the post-Kyoto period.

- Instituting a minimum price for auctioned allowances and allowing REDD credits to replace auctioned allowances. Allowance buyers would thus have an incentive to buy REDD credits until their price reaches the minimum price.

- Increasing demand for credits by tightening the reduction objectives of industrialized nations, or by obtaining binding commitments from some developing nations.

- $\quad$ Allowing companies to bank credits for future use, when carbon prices are expected to rise.

\section{F. The medium-term issue: full incorporation of forests in the international carbon market}

The UN Climate conference of Copenhagen, scheduled at the end of 2009, is expected to decide on the details of the link between forests and the international carbon market in the short term. A little before or after, the new rules of the EU ETS will largely decide on the fate of the forestry sector in the carbon market. These decisions will be based on the balance between the risks and opportunities of the different approaches described in this research report.

Carbon markets have so far been the main economic tool in the fight against climate change, and they are likely to remain so. They have proven their ability to reduce fossil fuels emissions, through the first phase of the European Emissions Trading Scheme. However, carbon markets have largely failed to dent the emissions from the forestry sector. The complexity and the patchiness of existing mechanisms - for forest management in industrialized countries and for reforestation in developing countries - are partly responsible for this failure. As $15-20 \%$ of total anthropogenic emissions come from the forestry sector, avoiding dangerous climate change will be difficult without an efficient mechanism to contain and reduce forest emissions. Notwithstanding the upcoming decision on a REDD mechanism, the full incorporation of forests in the international carbon market is thus likely to become an increasingly pressing issue.

A full incorporation means, in the long run, that countries are accountable for both sequestration and emissions from the forestry sector. After the compromise reached in Accra on "compensated conservation", the forestry sector seems closer than any other sector to this kind of sectoral agreement. The next negotiating issue will be to determine at what pace emerging economies will take a share of the costs implied by a sectoral agreement on forests. 
Climate Report No 14 - Reducing Emissions from Deforestation and Degradation: what Contribution from Carbon Markets? 
Annex 1. Published Figures of Emissions from Deforestation

\section{- The IPCC global estimate}

To obtain estimates of emissions from deforestation, one must overlay two types of information: the surface extent of deforestation and the amount of biomass that used to be stored there. Through remote sensing techniques, the measurement of deforestation extent is getting more and more accurate: as explained in part III, automated or visual interpretation of satellite images allow precise measurements of forest extent for every patch of land. Such an exhaustive measurement of forest biomass however is not yet feasible: the only way to ascertain it is a field inventory, which is too time-consuming to be carried out for every hectare of forest at the country scale. Nevertheless, compilations of scientific studies and forest inventories can provide enough data to construct fairly precise biomass maps. Based on such compilations, the IPCC good practices guidelines include peer-reviewed methods for measuring biomass and deforestation emissions endorsed by high-level international scientists.

The IPCC figure of $5.8 \pm 4 \mathrm{GtCO}_{2} \mathrm{e} /$ year in the 1990 s comes from the compilation of two global studies. One study, by Houghton, relies on the country statistics compiled by the FAO for deforestation rates. The other, by DeFries, relies on coarse resolution satellite imagery. For biomass accounting, both studies use Houghton's "book-keeping" method. $5.8 \mathrm{GtCO}_{2} \mathrm{e} /$ year is the average between the best guesses of each study, while $1.8 \mathrm{GtCO}_{2} \mathrm{e} / y e a r$ is the lower end of the estimate by DeFries and $9.8 \mathrm{GtCO}_{2} \mathrm{e} /$ year is the higher end of the estimate by Houghton.

As all countries in the world do not monitor their forests with great accuracy, satellite-based estimates are generally deemed more reliable at the global scale. Moreover, a later study by Achard, using a mix of coarse and medium resolution satellite images, produced independent estimates similar to DeFries for the 1990s. This is why we reckon that the best guess of DeFries at $3.8 \mathrm{GtCO}_{2} \mathrm{e} / y e a r$ is closer to the real figure than the average of $5.8 \mathrm{GtCO}_{2} \mathrm{e} /$ year.

\section{- The FAO national estimates}

As mentioned in part III.A, several countries such as Brazil and India routinely monitor their forest extent from satellite data. A few scientists have also been estimating national deforestation rates of big countries (Brazil, Indonesia, ...) with remote sensing data. But the only information available at the country scale with global coverage comes from the FAO Forest Resource Assessment. As this data set relies on the statistics that each country provides to the FAO, it is more uncertain, especially for countries that do not use satellite imagery for their forest inventories. Moreover, this compilation only tells about net forest cover change without separating gross deforestation from reforestation. That is why one may be surprised when comparing the FAO figures with remote sensing data when it is available: for Indonesia, it is three times higher than what Hansen estimated recently estimated from satellites. The same goes for global deforestation rates: the rates of the 1990s are probably closer to the satellite-based estimates of 8-9 million hectares per year than to the FAO estimate of 13 million hectares per year.

Yet, for all its flows, the FAO dataset is the only one to provide trends at the country level and, thanks to this precious specificity, it is often used by scientists and negotiators alike. 
ANNEX 2. THE COST OF AVOIDING DEFORESTATION - ESTIMATES FROM BOTTOM-UP APPROACHES

\begin{tabular}{|c|c|c|c|c|}
\hline Location & $\begin{array}{r}\text { Cost estimate } \\
(€ / \text { tCO2e })\end{array}$ & Basis of cost estimate & Change of activities & Source \\
\hline \multicolumn{5}{|c|}{ Avoided deforestation } \\
\hline Bolivia & 0.7 & Opportunity cost (national scale) & Conservation vs cattle and soybeans & $\begin{array}{r}\text { Grieg-Gran } 2006 \& \\
\text { Stern } 2006\end{array}$ \\
\hline Bolivia & 0.8 & Opportunity cost & Conservation vs soybeans & Silva-Chavez 2005 \\
\hline Brazil & 0.4 & $\begin{array}{l}\text { Opportunity cost (national scale) } \\
\text { excluding the most expensive } 6 \%\end{array}$ & $\begin{array}{r}\text { soybeans, cassava, rice, bananas, } \\
\text { sugarcane, pineapples, tree plantations } \\
\text { Sustainable timber vs cattle, soybeans \& }\end{array}$ & $\begin{array}{r}\text { Grieg-Gran } 2006 \& \\
\text { Stern } 2006\end{array}$ \\
\hline Brazil & 0.5 & of land) & unsustainable timber & $\begin{array}{r}\text { Nepstad } 2007 \\
\text { Diaz \& Schwartzman }\end{array}$ \\
\hline Brazil & $0,5-2$ & Opportunity cost & $\begin{array}{l}\text { Conservation vs timber and cattle } \\
\text { Conservation vs timber, cattle and }\end{array}$ & $\begin{array}{r}2005 \\
\text { Diaz \& Schwartzman }\end{array}$ \\
\hline Brazil & $2,5-4$ & Opportunity cost & soybeans & $\begin{array}{r}2005 \\
\text { Chomitz } 2006 \text { from }\end{array}$ \\
\hline Brazil & 0.9 & Opportunity cost & Nut extraction vs improved pasture & $\begin{array}{r}\text { Tomich } 2005 \\
\text { Chomitz } 2006 \text { from }\end{array}$ \\
\hline Brazil & 0.0 & Opportunity cost & $\begin{array}{r}\text { Nut extraction vs traditional pasture } \\
\text { Sustainable timber vs cattle, soybeans \& }\end{array}$ & Tomich 2005 \\
\hline Brazil & 1.0 & Opportunity cost (national scale) & unsustainable timber & Nepstad 2007 \\
\hline Panama & 0.7 & Opportunity cost & $\begin{array}{r}\text { Conservation vs cattle } \\
\text { Conservation vs shifting cultivation, }\end{array}$ & $\begin{array}{r}\text { Potvin } 2008 \\
\text { Grieg-Gran } 2006 \&\end{array}$ \\
\hline Cameroon & 0.7 & Opportunity cost (national scale) & 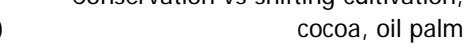 & Stern 2006 \\
\hline Cameroon & 1.9 & Opportunity cost & Conservation vs shifting cultivation & $\begin{array}{l}\text { Bellassen \& Gitz } 2008 \\
\quad \text { Chomitz } 2006 \text { from }\end{array}$ \\
\hline Cameroon & 2.0 & Opportunity cost & Timber vs intensive cocoa & $\begin{array}{r}\text { Tomich } 2005 \\
\text { Chomitz } 2006 \text { from }\end{array}$ \\
\hline Cameroon & 1.2 & Opportunity cost & $\begin{array}{l}\text { Timber vs extensive cocoa } \\
\text { Timber vs short fallow shifting }\end{array}$ & $\begin{array}{r}\text { Tomich } 2005 \\
\text { Chomitz } 2006 \text { from }\end{array}$ \\
\hline Cameroon & 0.7 & Opportunity cost & cultivation & $\begin{array}{r}\text { Tomich } 2005 \\
\text { Chomitz } 2006 \text { from }\end{array}$ \\
\hline Cameroon & 0.5 & Opportunity cost & Timber vs long fallow shifting cultivation & $\begin{array}{r}\text { Tomich } 2005 \\
\text { Chomitz } 2006 \text { from }\end{array}$ \\
\hline $\begin{array}{l}\text { Cameroon } \\
\text { Democratic Republic }\end{array}$ & 1.9 & Opportunity cost & $\begin{array}{r}\text { Timber vs oil palm } \\
\text { Conservation vs shifting cultivation, }\end{array}$ & $\begin{array}{r}\text { Tomich } 2005 \\
\text { Grieg-Gran } 2006 \&\end{array}$ \\
\hline $\begin{array}{l}\text { of Congo } \\
\text { Democratic Republic }\end{array}$ & 0.7 & $\begin{array}{l}\text { Opportunity cost (national scale) } \\
\text { Price paid locally by palm oil }\end{array}$ & cocoa, oil palm & Stern 2006 \\
\hline of Congo & 0.6 & companies & $\begin{array}{l}\text { Conservation vs oil palm } \\
\text { Conservation vs small-scale maize and }\end{array}$ & $\begin{array}{r}\text { Laporte } 2007 \\
\text { Grieg-Gran } 2006 \&\end{array}$ \\
\hline Ghana & 0.9 & Opportunity cost (national scale) & $\begin{array}{r}\text { cassava } \\
\text { Conservation vs timber, maize and }\end{array}$ & Stern 2006 \\
\hline Ghana & 5.2 & Opportunity cost & cassava & Osafo 2005 \\
\hline Madagascar & $0,5-2,8$ & Opportunity cost & $\begin{array}{l}\text { Conservation vs timber and rice } \\
\text { Conservation vs oil palm, rubber, rice, }\end{array}$ & $\begin{array}{r}\text { Kremen } 2000 \\
\text { Grieg-Gran } 2006 \&\end{array}$ \\
\hline Indonesia & 0.9 & Opportunity cost (national scale) & cassava & $\begin{array}{r}\text { Stern } 2006 \\
\text { Chomitz } 2006 \text { from }\end{array}$ \\
\hline Indonesia & 0.0 & Opportunity cost & Timber vs rubber & $\begin{array}{r}\text { Tomich } 2005 \\
\text { Chomitz } 2006 \text { from }\end{array}$ \\
\hline Indonesia & 0.3 & Opportunity cost & $\begin{array}{l}\text { Timber vs oil palm } \\
\text { Conservation vs oil palm, rubber, rice, }\end{array}$ & $\begin{array}{r}\text { Tomich } 2005 \\
\text { Grieg-Gran } 2006 \&\end{array}$ \\
\hline Malaysia & 1.1 & Opportunity cost (national scale) & cassava & $\begin{array}{r}\text { Stern } 2006 \\
\text { Grieg-Gran } 2006 \&\end{array}$ \\
\hline Papua New Guinea & 1.7 & Opportunity cost (national scale) & Conservation vs oil palm, staple crops & Stern 2006 \\
\hline
\end{tabular}

Estimates from bottom-up approaches point very low costs of avoiding deforestation, ranging from negative values (meaning that avoiding deforestation is theoretically already profitable) to $5.2 € / \mathrm{CCO}_{2} \mathrm{e}$ in Ghana.

Source: Mission Climat of Caisse des Dépôts. 
Achard et al., "Improved estimates of net carbon emissions from land cover change in the tropics for the 1990s", Global Biogeochemical Cycles, 2004

Anger and Sathaye, "Reducing Deforestation and Trading Emissions: Economic Implications for the postKyoto Carbon Market", Center for European Economic Research, 2008

Arima et al., "Cattle Ranching in the Amazon: Trends and Implications for Environmental Conservation", Imazon, 2006

Asner et al., "Selective Logging in the Brazilian Amazon", Science 310, 480-482, 2005

Brown, "Monitoring and Accounting of Greenhouse Gas from Forest Degradation", presentation given at the AFD workshop on forest degradation in Paris, 2008

Capoor and Ambrosi, "State and Trends of the Carbon Market 2008", World Bank Institute, 2008

Chomitz, "At Loggerheads? Agricultural Expansion, Poverty Reduction and Environment in the Tropical Forests", World Bank Policy Research Report, 2006

Chomitz and Wertz-Kanounnikoff, "Measuring the initial impacts on deforestation of Mato Grosso's program for environmental control”, World Bank Policy Research Working Paper, 2005

Ciais and Piao, "Variability and Recent Trends in the African Carbon Balance", submitted, 2008

Combes et al., "A methodology to estimate impacts of domestic policies on deforestation: Compensated Successful Efforts for "avoided deforestation" (REDD)", Ecological Economics, 2008

Convery, Ellerman \& De Perthuis, "The European Carbon Market in Action: Lessons from the First Trading Period - Intermediate report”, UCD, MIT, Mission Climat, 2008

Curran et al., "Lowland forest loss in protected areas of Indonesian Borneo", Science, 2004

DeFries et al., "Reducing Emissions from Deforestation in Developing Countries: Considerations for Monitoring and Measuring", GOFC-GOLD, 2006

DeFries et al., "Carbon emissions from tropical deforestation and regrowth based on satellite observations for the 1980s and 1990s", PNAS, 2002

Duveiller et al., "Deforestation in Central Africa: Estimates at regional, national and landscape levels by advanced processing of systematically-distributed Landsat extracts", Remote Sensing of Environment, 2008

FAO, "Global Forest Resources Assessment 2000: Main report", 2001

Fearnside, "Deforestation Control in Mato Grosso: A New Model for Slowing the Loss of Brazil's Amazon Forest", Royal Swedish Academy of Sciences, 2003

Geist and Lambin, "Proximate Causes and Underlying Driving Forces of Tropical Deforestation", BioScience, 2002

Gibbs et al., "Monitoring and estimating tropical forest carbon stocks: making REDD a reality", Environmental Research Letters, 2007

Gibbs et al., "Ecosystem carbon payback time for tropical biofuel expansion: The effects of changing yield and technology", submitted to Environmental Research Letters in April 2008

Griffiths, "Seeing REDD? Avoided deforestation and the rights of indigenous and local communities", Forest Peoples' Program, 2007

Hansen et al., "Humid tropical forest clearing from 2000 to 2005 quantified by using multitemporal and multiresolution remotely sensed data", PNAS, 2008 
Hyde et al., "Deforestation and Forest Land Use: Theory, Evidence, and Policy Implications", The World Bank Observer, 1996

Houghton, "Revised estimates of the annual net flux of carbon to the atmosphere from changes in land use and land management 1850-2000", Tellus, 2003

IPCC, "2006 IPCC Guidelines for National Greenhouse Gas Inventories”, 2006

IPCC, "Climate Change 2007, The Physical Science Basis", 2007 (Chapter 7)

IPCC, "Climate Change 2007, Mitigation", 2007 (Chapter 1)

Kaimowitz and Angelsen, "Economic Models of Tropical Deforestation: A Review", Center for International Forestry Research, 1998

Karousakis and Corfee-Morlot, "Financing Mechanisms to Reduce Emissions from Deforestation: Issues in Design and Implementation", OECD, 2007

Kindermann et al., "Global cost estimates of reducing carbon emissions through avoided deforestation", PNAS, 2008

Laporte et al., "Expansion of industrial logging in Central Africa", Science, 2007

Moutinho P. and Schwartzman S., "Tropical Deforestation and Climate Change", 2005

Rubio Alvarado and Wertz-Kanounnikoff, "Why are we seeing REDD?", IDDRI, 2007

Pearson et al., "Impact of logging on carbon stocks of forests: The Brazilian Amazon as a case study", USAID, 2006

Pirard and Karsenty, "Climate Change Mitigation: Should "Avoided Deforestation" (REDD) Be Rewarded?", to be published in Journal of Sustainable Forestry, 2009

Piris Cabezas and Keohane, "Reducing Emissions from Deforestation and Forest Degradation (REDD): Implications for the Carbon Market", Environmental Defense Fund, 2008

Saatchi et al., "Distribution of aboveground live biomass in the Amazon basin", Global Change Biology, 2007

Searchinger et al., "Use of U.S. Croplands for Biofuels Increase Greenhouse Gases Through Emissions from Land Use Change", Sciencexpress, February $7^{\text {th }}, 2008$

Soares-Filho et al., "Modelling conservation in the Amazon basin", Nature, 2006

Silva Dias et al., "Cloud and rain processes in biosphere-atmosphere interaction context in the Amazon region", Journal of Geophysical Research, 2002

Stickler et al., "Readiness for REDD: A preliminary global assessment of tropical forested land suitability for agriculture", WHRC, 2007

Wunder, "The Efficiency of Payments for Environmental Services in Tropical Conservation", Conservation Biology, 2007

Wunder, "Oil Wealth and the Fate of the Forest - A Comparative Study of Eight Tropical Developing Countries", Routledge, 2003 
Climate Report No 14 - Reducing Emissions from Deforestation and Degradation: what Contribution from Carbon Markets? 


\section{Climate Reports}

$N^{\circ} 1^{*} \quad$ Les fonds d'investissement dans les actifs carbone : état des lieux ARIANE DE DOMINICIS - January 2005

$N^{\circ} 2^{*} \quad$ Plan National d'Allocation des Quotas et territoires

EMmANUEL ARNAUD - March 2005

$\mathrm{N}^{\circ} 3$ Les plateformes de marché et le fonctionnement du système de quotas $\mathrm{CO}_{2}$ ROMAIN FREMONT - June 2005

$\mathrm{N}^{\circ} 4^{*} \quad$ Les enjeux de la réduction des émissions de gaz à effet de serre dans le bâtiment EMMANUEL ARNAUD - September 2005

$N^{\circ} 5$ Domestic Offset Projects ARIANE DE DOMINICIS - September 2005

$N^{\circ} 6^{*} \quad$ Agriculture et réduction des émissions de gaz à effet de serre BENOIT Leguet - September 2005

$\mathrm{N}^{\circ} 7^{*} \quad$ Fonds d'investissement dans les actifs $\mathrm{CO}_{2}$ : l'accélération ARIANE DE DOMINICIS - November 2005

$\mathrm{N}^{\circ} 8 \quad$ Overview of European National Allocation Plans CLAIRE DUfOUR \& ALEXIA LESEUR - April 2006

$N^{\circ} 9 \quad$ Trading in the Rain; Rainfall and European Power Sector Emissions KATIA HOUPERT \& ARIANE DE DOMINICIS - July 2006

N 10 Growth without Warming? The Carbon Intensity in the Developed Economies Anaïs Delbosc, Jan Horst Keppler \& AlexiA LeSEUR - January 2007

$N^{\circ} 11$ The Emergence of Voluntary Carbon Offsetting VALENTIN BELlassen \& Benoît Leguet - September 2007

N 12 Carbon Procurement Vehicles: The Influx of Private Capital IAN THOMAS COCHRAN \& BENOÎT LEGUET - October 2007

$\mathrm{N}^{\circ} 13$ The European $\mathrm{CO}_{2}$ Market Viewed Through the CITL: Allowance Trading Patterns in the Trial Period RAPHAEL TROtignon \& ANAïs Delbosc - June 2008

\section{Reports}

Expanding the Means to Combat Climate Change through Domestic Offset Projects (Executive Summary)

Emmanuel Arnaud, Ariane de Dominicis, Benoit leguet, Alexia Leseur \& Christian de PERTHUIS - November 2005

The European Carbon Market in Action: Lessons from the First Trading Period, Interim Report Frank Convery, Denny Ellerman \& Christian de Perthuis - March 2008

* Only available in French.

\section{All Mission Climat publications are available in English at:}


Publication Director:

Christian de Perthuis

+33158502262

christian.deperthuis@caissedesdepots.fr

Contacts in Mission Climat:

EMILIE AlBerola

emilie.alberola@caissedesdepots.fr

+33158504176

MAY ARMSTRONG

+33158507627

may.armstrong@caissedesdepots.fr

VALENTIN BELLASSEN

+33158501975

valentin.bellassen@caissedesdepots.fr

Cecile Bordier

+33158508520

cecile.bordier@caissedesdepots.fr

MALIKA BOUMAZA

malika.boumaza@caissedesdepots.fr

+33158503738

IAN COCHRAN

+33158504177

ian.cochran@caissedesdepots.fr

ANAïs DELBOSC

+33158509928

anais.delbosc@caissedesdepots.fr

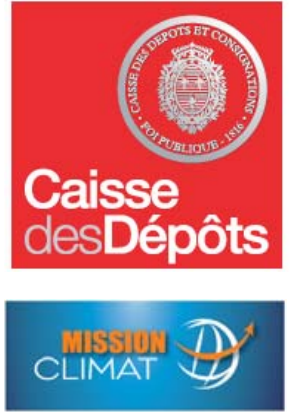

This Climate Report was produced within the scope of the Mission Climat of Caisse des Dépôts.

The authors take sole responsibility for any errors or omissions.

Mission Climat of Caisse des Dépôts is a resource centre that leads and coordinates research and development work in the field of action against climate change.
ANITA DROUET

anita.drouet@caissedesdepots.fr

Chaoling Feng

chaoling.feng@caissedesdepots.fr

PierRe GuigoN

pierre.guigon@caissedesdepots.fr

MoRgan HERVÉ-MignUCCI

morgan.herve-mignucci@caissedesdepots.fr

CATE Hight

cate.hight@caissedesdepots.fr

BENOIT LEGUET

benoit.leguet@caissedesdepots.fr

ALEXIA LESEUR

alexia.leseur@caissedesdepots.fr

MARIA MANSANET-BATALLER

maria.mansanet@caissedesdepots.fr

THERESE SIBILLE

therese.sibille@caissedesdepots.fr

RAPHAËL TROTIGNON

raphael.trotignon@caissedesdepots.fr
+33158508519

+33158509839

+33158508517

+33158509977

+33158509819

+33158509818

+33158504130

+33158508522

+33158509820

+33158509604 